\title{
Hopfield Neural Network Optimized Fuzzy Logic Controller for Maximum Power Point Tracking in a Photovoltaic System
}

\author{
Subiyanto, Azah Mohamed, and Hussain Shareef \\ Department of Electrical, Electronic, and Systems Engineering, National University of Malaysia, Bangi, 43600 Selangor, Malaysia \\ Correspondence should be addressed to Subiyanto, biyantote_unnes@yahoo.com \\ Received 18 February 2011; Accepted 15 July 2011 \\ Academic Editor: Songyuan Dai \\ Copyright () 2012 Subiyanto et al. This is an open access article distributed under the Creative Commons Attribution License, \\ which permits unrestricted use, distribution, and reproduction in any medium, provided the original work is properly cited.
}

This paper presents a Hopfield neural network (HNN) optimized fuzzy logic controller (FLC) for maximum power point tracking in photovoltaic (PV) systems. In the proposed method, HNN is utilized to automatically tune the FLC membership functions instead of adopting the trial-and-error approach. As in any fuzzy system, initial tuning parameters are extracted from expert knowledge using an improved model of a PV module under varying solar radiation, temperature, and load conditions. The linguistic variables for FLC are derived from, traditional perturbation and observation method. Simulation results showed that the proposed optimized FLC provides fast and accurate tracking of the PV maximum power point under varying operating conditions compared to that of the manually tuned FLC using trial and error.

\section{Introduction}

Because of the demand for electric energy and environmental issues such as pollution and the effects of global warming, renewable energy sources are considered as an option for generating clean energy technologies [1]. Among them, the photovoltaic (PV) energy from solar radiation has received great attention, as it appears to be one of the most promising renewable energy sources in the world [2]. PV systems have been developed to supply clean energy for fulfilling the energy demand required by the modern society. However, the widespread use of PV systems poses several challenges such as increasing the efficiency of energy conversion, ensuring the reliability of power electronic converters, and meeting the requirements for grid connection [3]. One step to overcome the problem of low energy conversion efficiency of $\mathrm{PV}$ modules and to get the maximum possible power is to extract maximum power from the PV system at every instant of time. To achieve this, it is mandatory to operate the PV systems close to its maximum power point (MPP). Maximum power point tracking (MPPT) system is an electronic system that plays a vital role in operating the $\mathrm{PV}$ modules in a manner that it produces it is maximum power according to the situation [4]. Many MPPT control strategies have been elaborated in the literature, starting with simple techniques such as voltage and current feedbackbased MPPT to more improved power-based MPPT such as the perturbation and observation $(\mathrm{P} \& \mathrm{O})$ technique and the incremental conductance technique [5].

Recently, fuzzy logic has been applied for tracking the MPP of PV systems in [6-9] because it has the advantages of being robust, design simplicity, and minimal requirement for accurate mathematical model. It is found that fuzzy logicbased $\mathrm{P} \& \mathrm{O}$ and hill climbing MPPT methods perform batter due to optimized perturbation. However, the fuzzy methods depend on careful selection of parameter, definition of membership function, and the fuzzy rules table. Developing fuzzy method also involves expert knowledge and experimentation in selecting parameters and membership functions. For this reason, adaptive fuzzy logic control [10] and parameter optimization techniques such as genetic algorithm [11] and particle swam optimization $[12,13]$ have been introduced to overcome the problem in MPPT algorithms.

A number of studies on MPPT have concentrated on the application of artificial neural network (ANN) [14, 15]. In most of these ANN-based methods, large number of field data considering atmospheric conditions are required to train the ANN. Moreover, the main problem of ANNbased methods are that it is system dependent and cannot be 


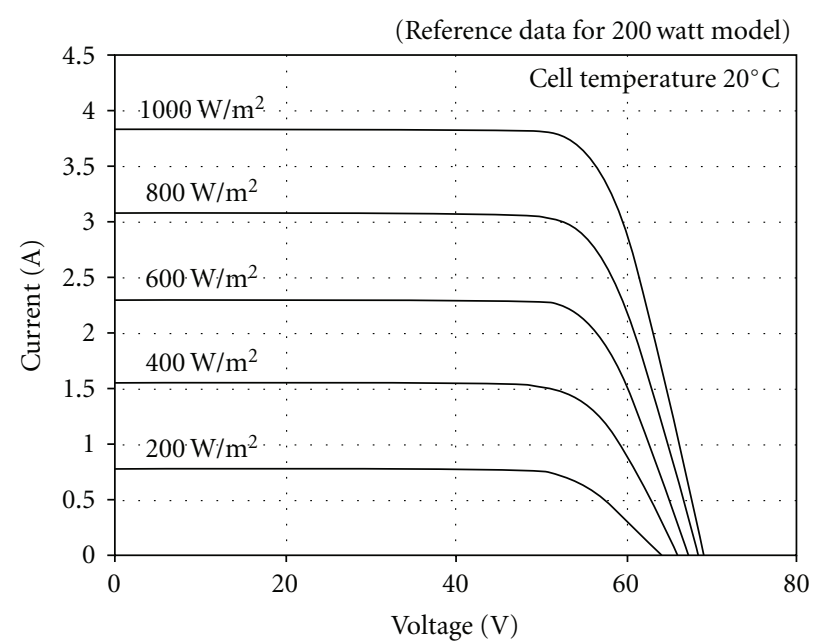

(a) Effect of irradiation

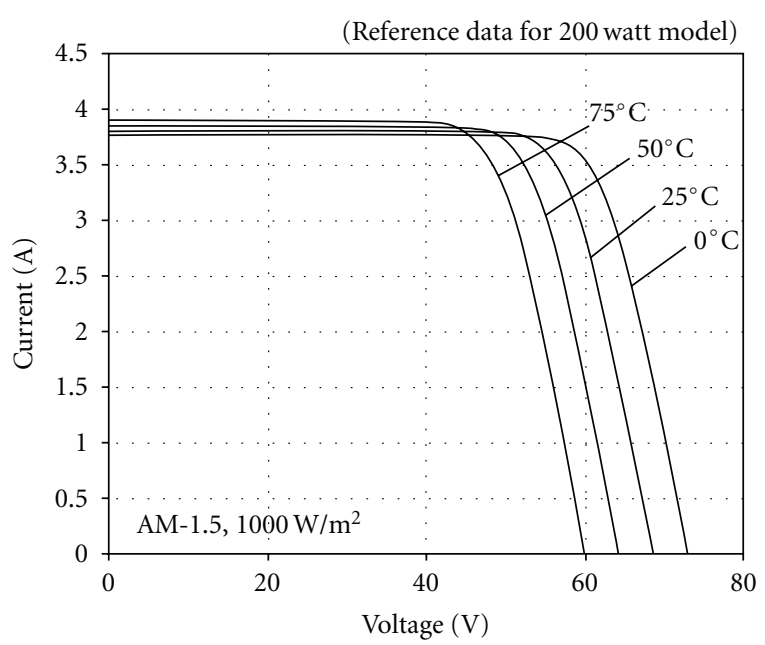

(b) Effect of temperature

FIgURE 1: $V$-I Characteristic of a typical PV module.

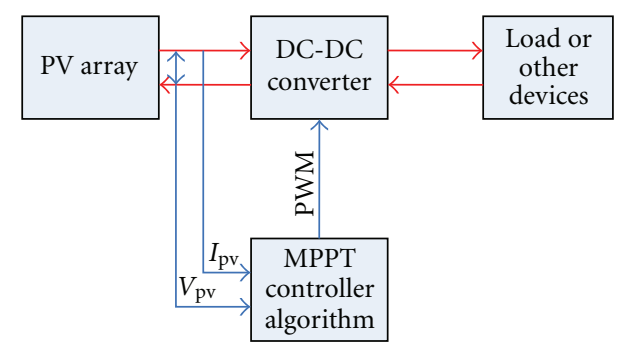

FIgure 2: MPPT controller in a PV system.

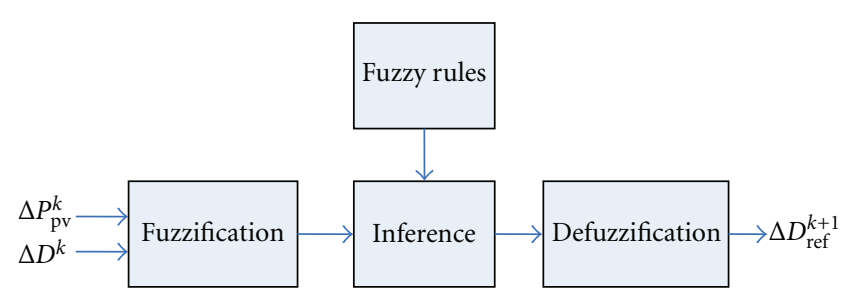

Figure 3: Components of a fuzzy logic controller.

implemented for PV arrays with different characteristics. In a related work, a voltage-based MPPT using ANN has been developed in which an optimal instantaneous voltage factor was determined from a trained ANN [16]. The inputs of the ANN consist of temperature module and solar irradiation.

The combined use of fuzzy logic and ANN to track maximum power point in PV systems can be found in $[17,18]$. In this method, ANN is trained offline using experimental data to define a reference voltage, which is the voltage at the maximum power point according to the PV array characteristic. The reference voltage is then compared to the instantaneous array voltage to generate a signal error. The signal error and change of the error are considered as the FLC inputs. The FLC generates a duty cycle value for the pulse width modulation (PWM) generator. The PWM is then

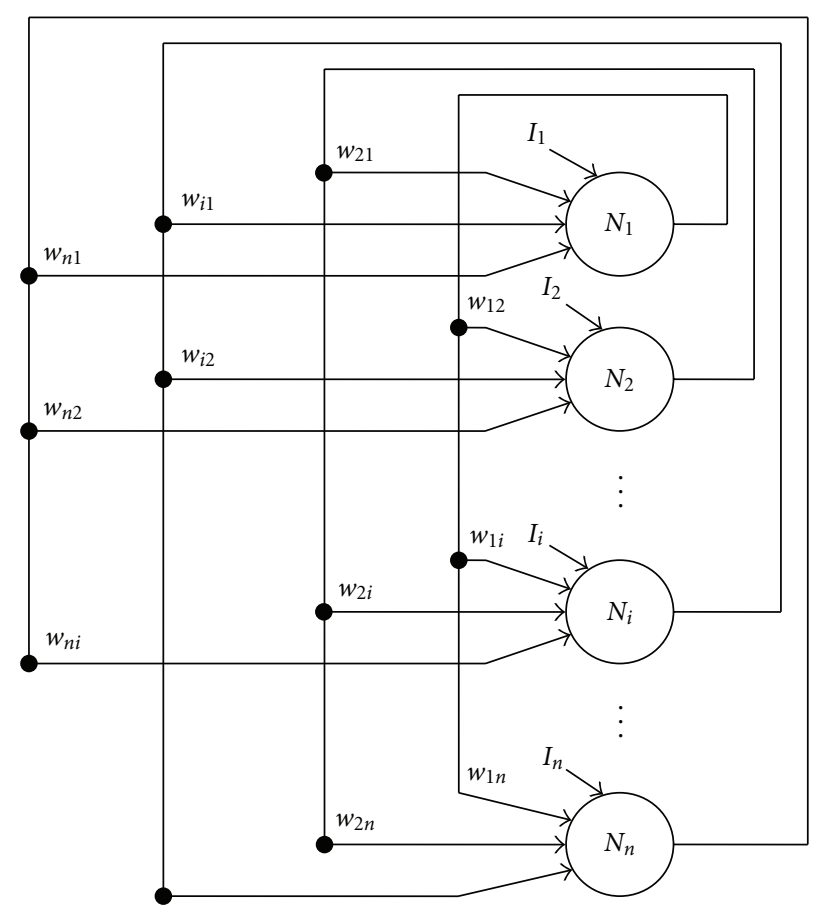

FIgure 4: Discrete Hopfield neural network.

applied to the switching of the boost converter connected to a PV array. A drawback of this method is that it needs much data for offline training.

In this paper, a new variant of intelligent technique is proposed and used together with fuzzy logic-based MPPT controller in a PV system. Here, the fuzzy logic MPPT controller is integrated with the Hopfield neural network (HNN) to optimize the membership function of the fuzzy system. The HNN has been applied to various fields since Hopfield proposed the model [19, 20]. In optimization problems, the HNN has a well-demonstrated capability of 


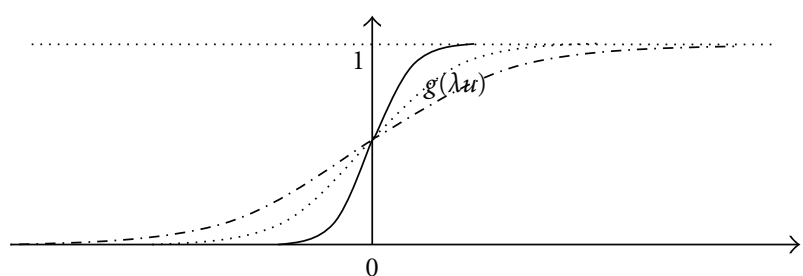

FIGURE 5: Curve of a sigmoid function.

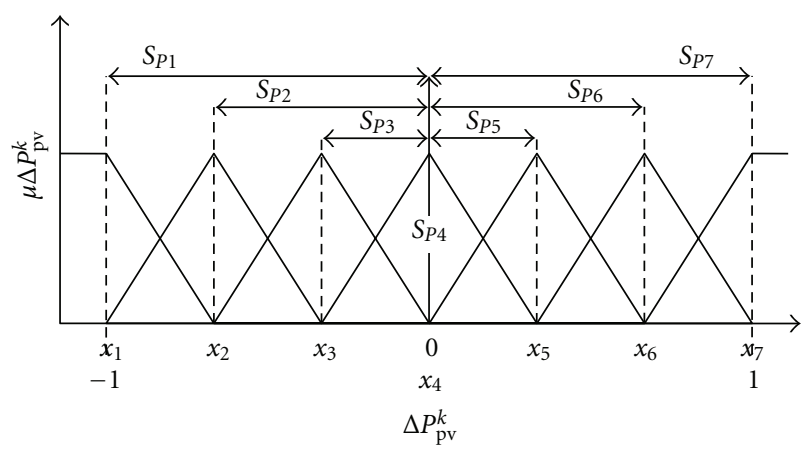

Figure 6: Membership functions coding for $\Delta P_{\mathrm{pv}}^{k}$.

finding solutions to complex tasks. HNN has been applied to solve optimization problems based on convergence of the energy function and coefficients weighting [21-23].

\section{Maximum Power Point Tracking and Fuzzy Logic}

PV is not a constant DC energy source but has variation of output power, which depends strongly on the current drawn by the load. Besides, PV characteristic also changes with temperature and irradiation variation [4]. Thus, the output voltage $(V)$ of $\mathrm{PV}$ varies with the current $(I)$. Figure 1 shows the characteristic of a $200 \mathrm{~W}$ Sanyo PV module [24]. The module can be used as a single system or it can be connected to other similar modules to increase the voltage and current. In multimodule systems, PV modules are wired in series and parallel to form a PV array. From Figure 1, it can be seen that the PV module voltage varies from $0 \mathrm{~V}$ until the open circuit voltage $\left(V_{\mathrm{oc}}\right)$ of the module. Similarly, the current varies from $0 \mathrm{~A}$ until the short circuit current $\left(I_{\mathrm{sc}}\right)$ of the module. The $V_{\mathrm{oc}}$ and $I_{\mathrm{sc}}$ of a PV module also depend on temperature and solar irradiation.

For any PV system, the output power is increased by tracking the maximum power point (MPP) of the system. To achieve this, an MPPT controller is required to track the optimum power of the PV system and it is usually connected to a boost converter located between the PV panel and load as shown in Figure 2 [6-8]. Many different control techniques such as the P\&O and fuzzy logic are used in the MPPT controller.

The main components of a fuzzy logic controller (FLC) are fuzzification, fuzzy rules inference, and defuzzification as shown in Figure 3. The input variables to the FLC are the change in power of $\mathrm{PV}\left(\Delta P_{\mathrm{pv}}^{k}\right)$ array and direction of change

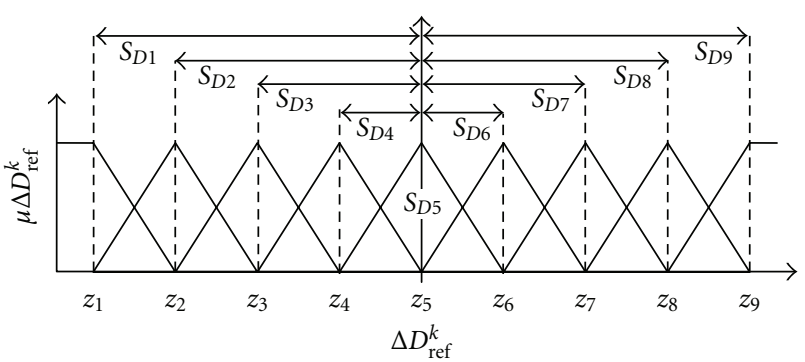

Figure 7: Membership functions coding for $\Delta D_{\text {ref }}^{k}$.

in duty cycle $\left(\Delta D^{k}\right)$ of boost converter whereas the output of the FLC is the change of the duty cycle that must be applied to control boost converter $\left(\Delta D_{\text {ref }}^{k+1}\right)$. The formulation for $\Delta P_{\mathrm{pv}}^{k}$ and $\Delta D^{k}$ can be expressed as follows:

$$
\begin{aligned}
P_{\mathrm{pv}}^{k} & =V_{\mathrm{pv}}^{k} \cdot I_{\mathrm{pv}}^{k}, \\
\Delta P_{\mathrm{pv}}^{k} & =P_{\mathrm{pv}}^{k}-P_{\mathrm{pv}}^{k-1}, \\
\Delta D^{k} & =D^{k}-D^{k-1},
\end{aligned}
$$

where, $P_{\mathrm{pv}}^{k}: \mathrm{PV}$ array output power at $k$ th iteration, $V_{\mathrm{pv}}^{k}$ : PV array output voltage at $k$ th iteration, $I_{\mathrm{pv}}^{k}$ : $\mathrm{PV}$ array output current at $k$ th iteration, $D^{k}$ : measured duty cycle to control switch of DC-DC converter at $k$ th iteration, $D_{\text {ref }}^{k+1}$ : duty cycle that must be applied to control switch of DC-DC converter at $(k+1)^{\text {th }}$ iteration, $\Delta$ : a small change.

The universe of discourse for the first input variable $\left(\Delta P_{\mathrm{pv}}^{k}\right)$ is assigned in terms of its linguistic variable by using seven fuzzy subsets which are denoted by negative large $(\mathrm{NL})$, negative medium (NM), negative small (NS), zero (Z), positive small (PS), positive medium (PM), and positive large $(\mathrm{PL})$. The universe of discourse for the second input variable $\left(\Delta D^{k}\right)$ defines the changes in direction of duty cycle which is classified into three fuzzy sets, namely, negative $(\mathrm{N})$, zero $(\mathrm{Z})$, and positive $(\mathrm{P})$. The output variable $\left(\Delta D_{\text {ref }}^{k}\right)$ is assigned in terms of its linguistic variable by using nine fuzzy subsets which are denoted by negative double large (NLL), negative large (NL), negative medium (NM), negative small (NS), zero $(\mathrm{Z})$, positive small (PS), positive medium (PM), positive large (PL), and positive double large (PLL). Then, the fuzzy rules are generated as shown in Table 1 with $\Delta P_{\mathrm{pv}}^{k}$ and $\Delta D^{k}$ as inputs while $\Delta D_{\text {ref }}^{k}$ as the output. This table is also known as fuzzy associative matrix (FAM). The fuzzy inference of the FLC is based on Mamdani's method, which is associated with the max-min composition. The defuzzification technique is based on the centroid method, which is used to compute the crisp output, $\Delta D_{\text {ref }}^{k}$.

\section{Design of Optimized FLC with HNN}

The proposed design is to develop optimal membership function of the FLC especially for MPPT in PV systems application. The HNN representation and the integration of HNN and FLC is described in the following subsections. 


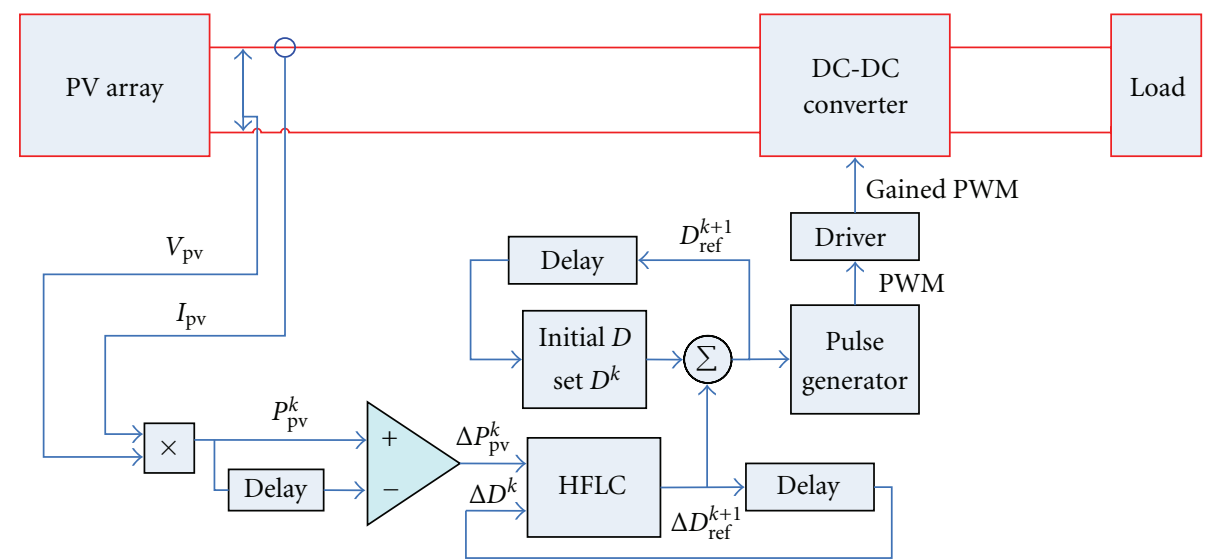

FIGURE 8: Physical implementation of PV MPPT system using HFLC.

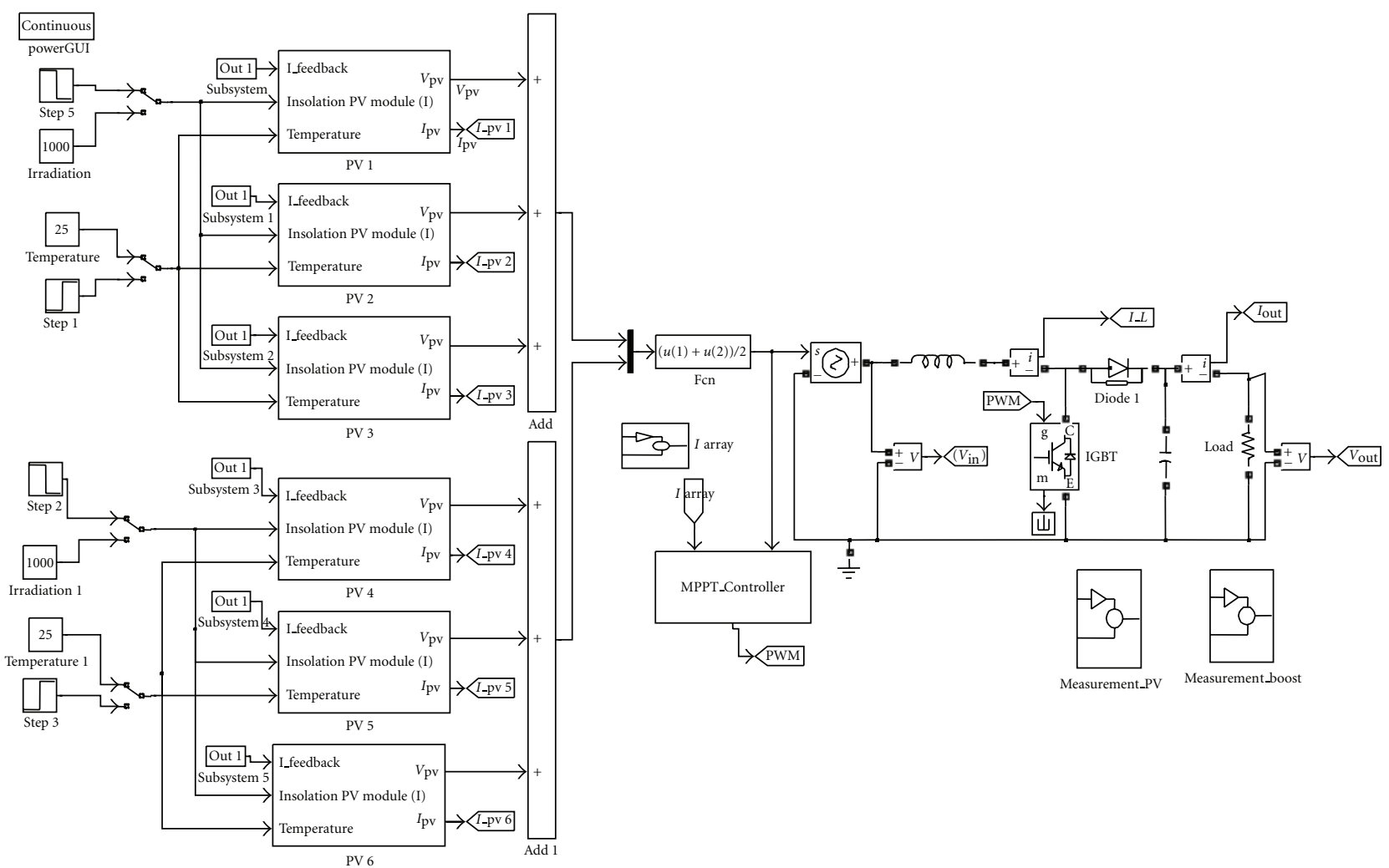

Figure 9: MATLAB simulation model of a PV MPPT controller.

TABLE 1: Fuzzy rules for the proposed FLC.

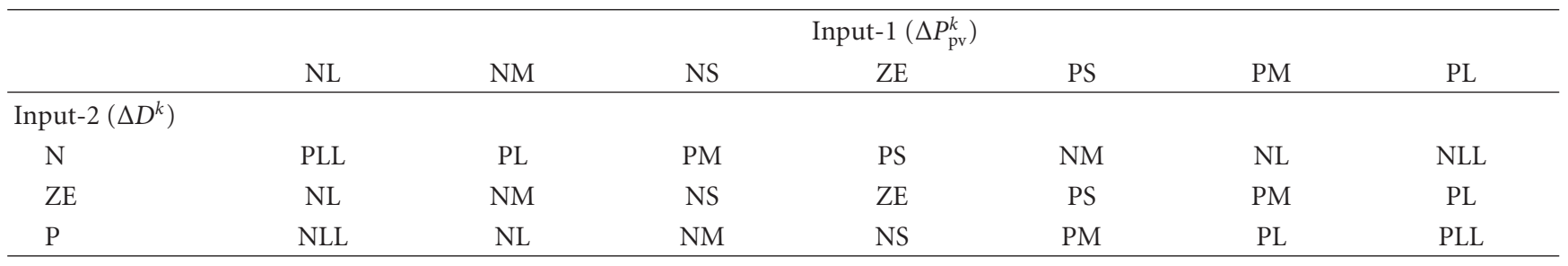




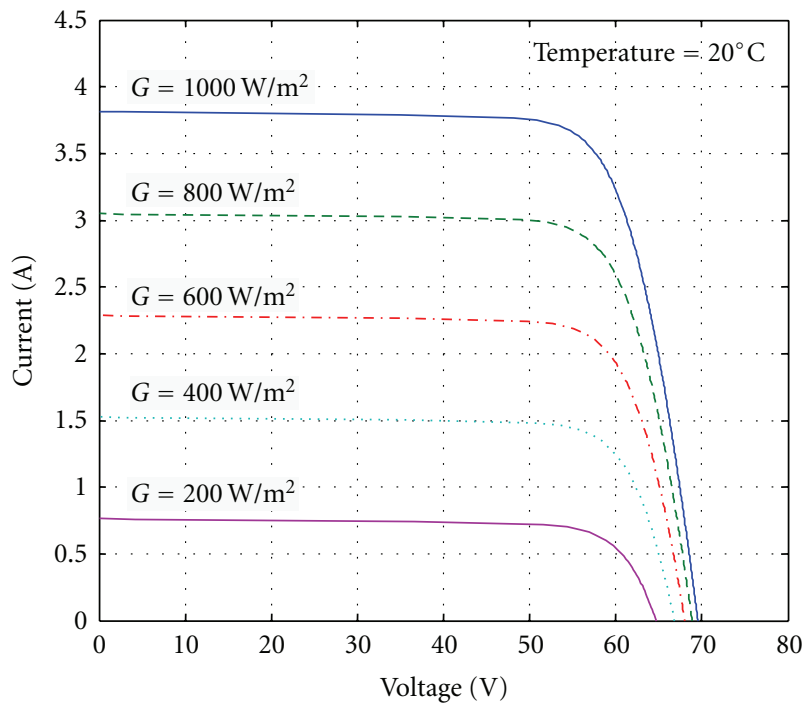

FIGURE 10: Effects of solar radiation at constant temperature on the PV module.

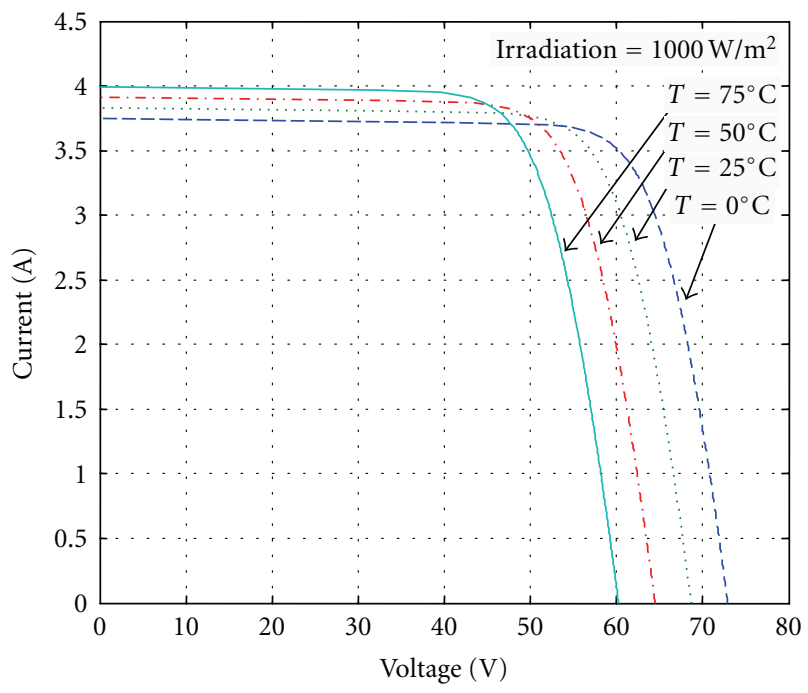

FIGURE 11: Effects of temperature at constant solar radiation on the PV module.

3.1. Hopfield Neural Network Representation. The HNN network is useful for associative memory and optimization in a symmetrical structure. The basic structure of the HNN is shown in Figure 4 [25].

The HNN uses a two-state threshold "neuron" that follows a stochastic algorithm where each neuron, or processing element, $N_{i}$ has two states with values either 0 or 1 . The inputs of each neuron come from two sources; external inputs, $I_{i}$, and inputs from other neurons, $N_{j}$. The total input to neuron $N_{i}$ is given by

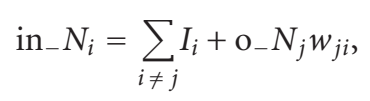

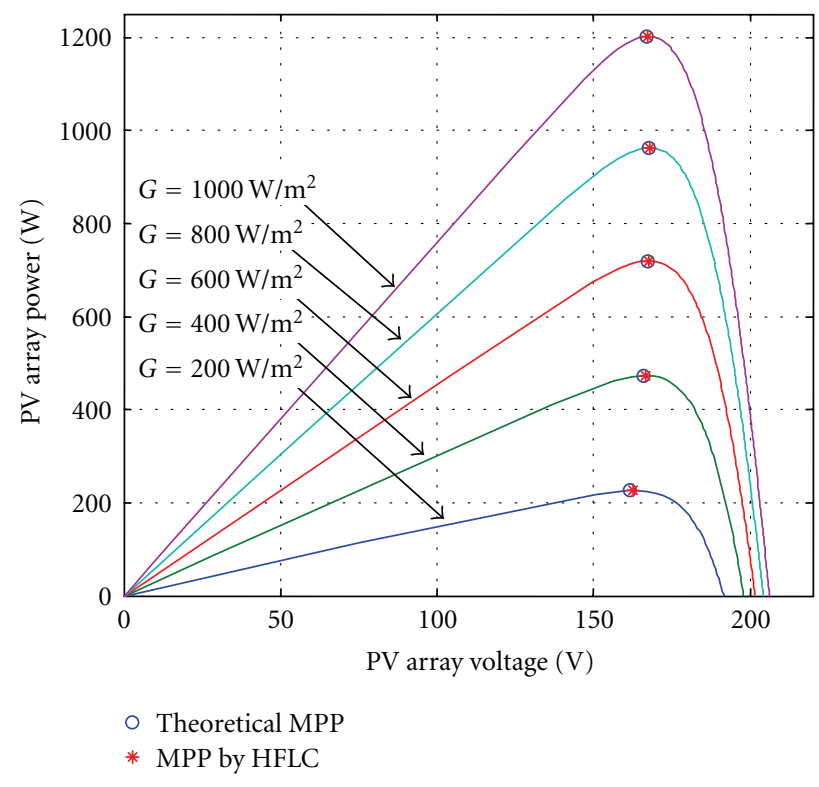

FIGURE 12: Performance of the HFLC-based MPPT under various irradiation at constant temperature $T=25^{\circ} \mathrm{C}$.

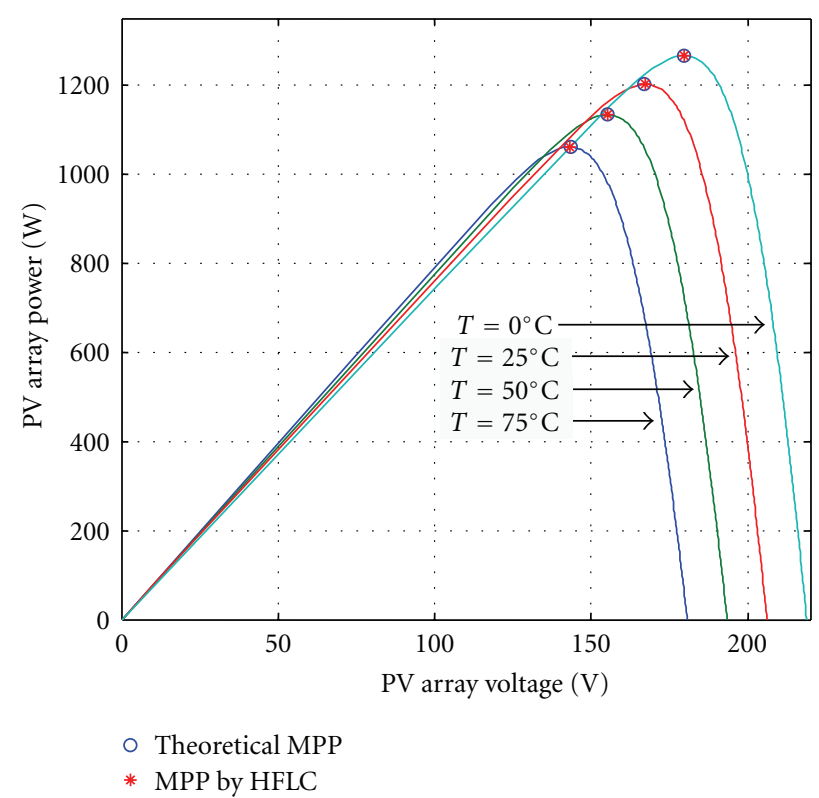

Figure 13: Performance of the HFLC based MPPT under various temperatures at constant irradiation $G=1000 \mathrm{~W} / \mathrm{m}^{2}$.

where in $\_N_{i}$ : total input to neuron $i, w_{j i}$ : synaptic interconnection strength from neuron $N_{i}$ to neuron $N_{j}, I_{i}$ : external input to neuron $N_{i}, \mathrm{O}_{-} N_{j}$ : output of neuron $N_{j}$.

Each neuron samples its input at random times. It changes the value of its output or leaves it fixed according to a threshold rule with thresholds $\theta_{i}$ :

$$
\mathrm{o}_{-} N_{i}= \begin{cases}1, & \text { if in }-N_{i} \geq \theta_{i}, \\ 0, & \text { if in } \_N_{i}<\theta_{i} .\end{cases}
$$




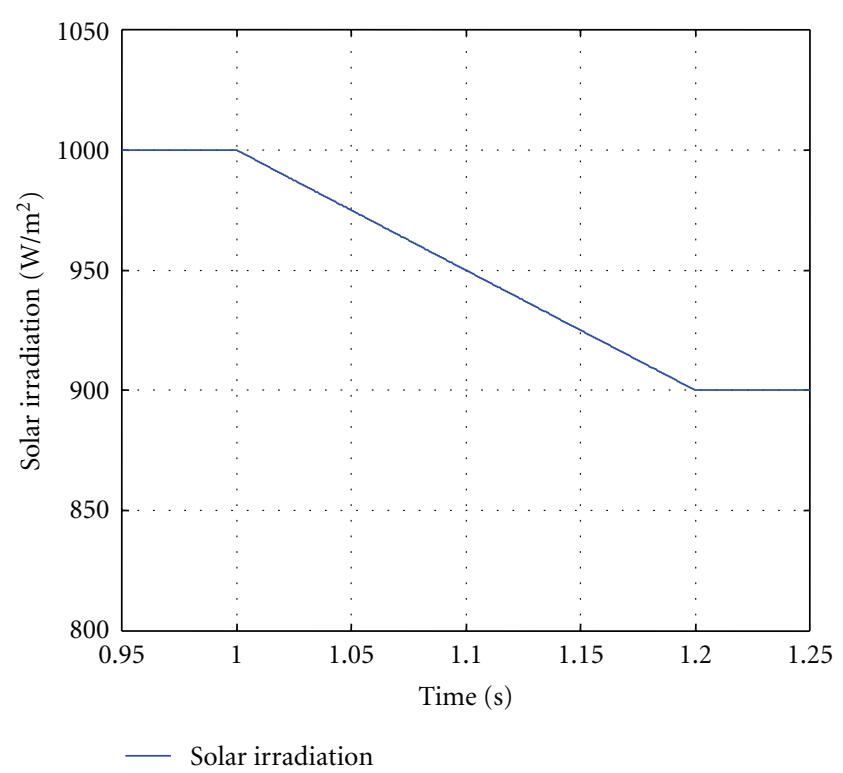

FIGURE 14: Slow change of irradiation from $1000 \mathrm{~W} / \mathrm{m}^{2}$ to $900 \mathrm{~W} / \mathrm{m}^{2}$.

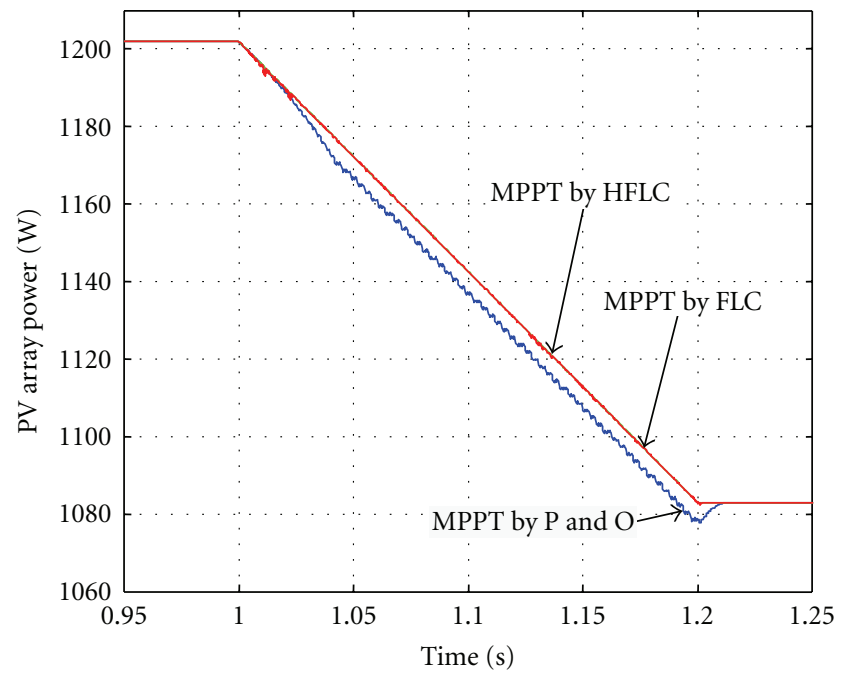

FIGURE 15: PV output power under slow irradiation change from $1000 \mathrm{~W} / \mathrm{m}^{2}$ to $900 \mathrm{~W} / \mathrm{m}^{2}$.

Then the energy function of the HNN is defined as $E=-\frac{1}{2} \sum_{i \neq j} \sum_{j} \mathrm{o}_{-} N_{i} \cdot \mathrm{o}_{-} N_{j} \cdot w_{i j}-\sum_{i} I_{i} \cdot \mathrm{o}_{-} N_{i}+\sum_{i} \theta_{i} \cdot \mathrm{o}_{-} N_{i}$.

The change in $E$ due to the changing state of neuron $N_{i}$ by $\Delta \mathrm{o}_{-} N_{i}$ is given by

$$
\Delta E=-\left[\sum_{j} \mathrm{o}_{-} N_{j} \cdot w_{i j}+I_{i}-\theta_{i}\right] \Delta \mathrm{o}_{-} N_{i},
$$

where $\Delta \mathrm{o}_{-} N_{i}$ is the change in the output of neuron $N_{i}$.

The continuous and deterministic model of the HNN is based on continuous variables and responses but retains all

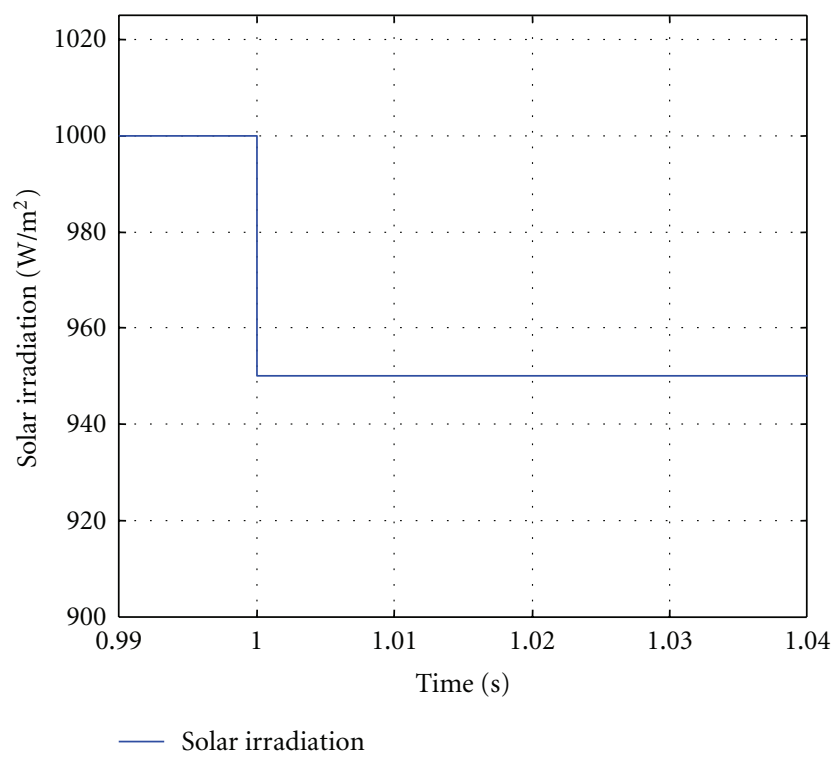

FIGURE 16: Drastic change in irradiation from $1000 \mathrm{~W} / \mathrm{m}^{2}$ to $950 \mathrm{~W} / \mathrm{m}^{2}$.

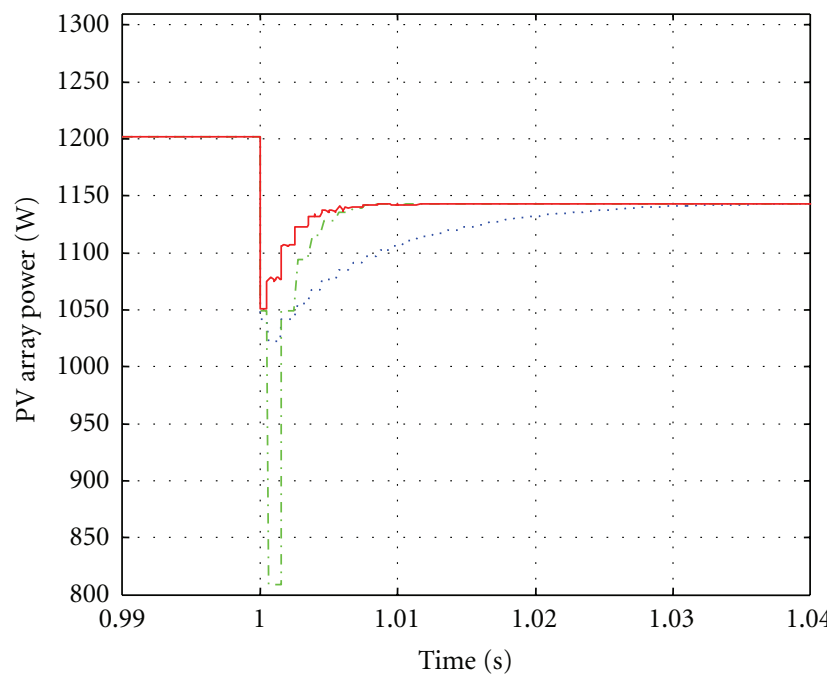

..... MPPT by $\mathrm{P}$ and $\mathrm{O}$

-.. MPPT by FLC

— MPPT by HFLC

FIGURE 17: PV output power under drastic irradiation change from $1000 \mathrm{~W} / \mathrm{m}^{2}$ to $950 \mathrm{~W} / \mathrm{m}^{2}$.

of the significant behaviors of the original model described above. The output variable $\mathrm{o}_{-} N_{i}$ for neuron $N_{i}$ has values in the range of $0 \leq \mathrm{o} \_N_{i} \leq 1$ and the input-output function is a continuous and monotonically increasing function of the input in $-N_{i}$ to neuron $N_{i}$.

The dynamics of the neurons is defined as [18]

$$
\frac{d u_{i}}{d t}=\frac{-u_{i}}{\tau}+\sum_{j} w_{i j} \cdot o_{-} N_{j}+I_{i}
$$

where $\tau$ : a constant, $u_{i}$ : input of HNN. 


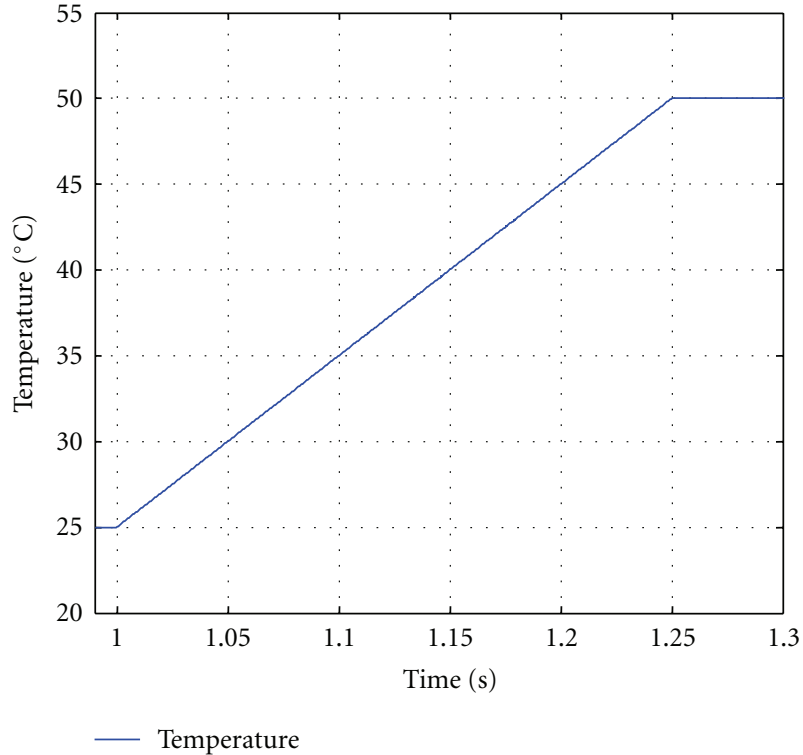

Figure 18: Slow change of temperatures from $25^{\circ} \mathrm{C}$ to $50^{\circ} \mathrm{C}$.

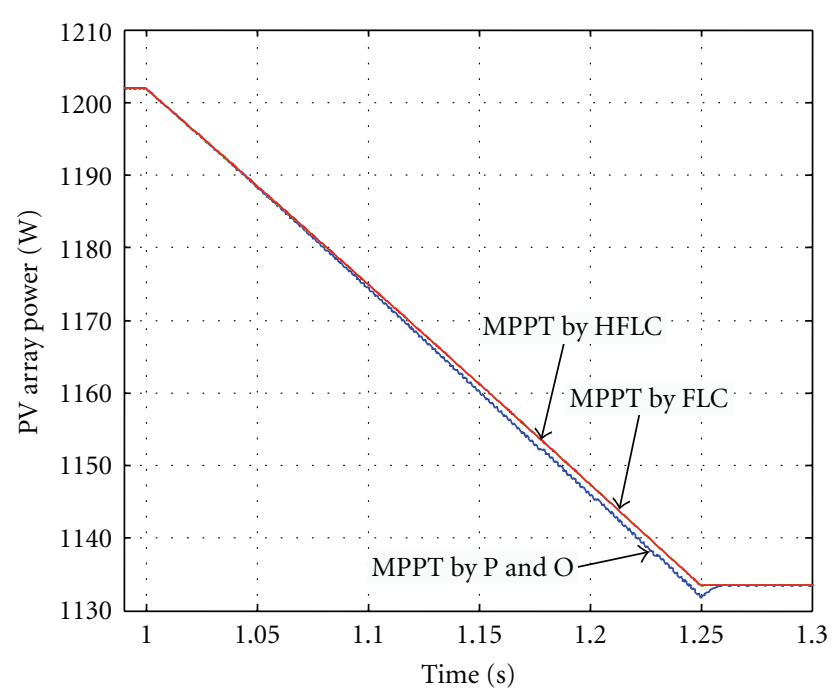

Figure 19: PV output power under slow temperature change from $25^{\circ} \mathrm{C}$ to $50^{\circ} \mathrm{C}$.

A typical output of neuron $N_{i}$ is a sigmoid function as shown in Figure 5. Mathematically it is given by

$$
\mathrm{o}_{-} N_{i}=g\left(\lambda u_{i}\right)=\frac{1}{1+e^{-\lambda u_{i}}},
$$

where $\lambda$ is the gain that determines the shape of the sigmoid function.

The energy function of the continuous HNN is similarly defined as [19]

$$
E=-\left[\frac{1}{2} \sum_{i=1}^{n} \sum_{j=1}^{n} w_{i j} \mathbf{o}_{-} N_{i} \cdot \mathbf{o}_{-} N_{j}+\sum_{i=1}^{n} I_{i} \mathbf{o}_{-} N_{i}\right],
$$

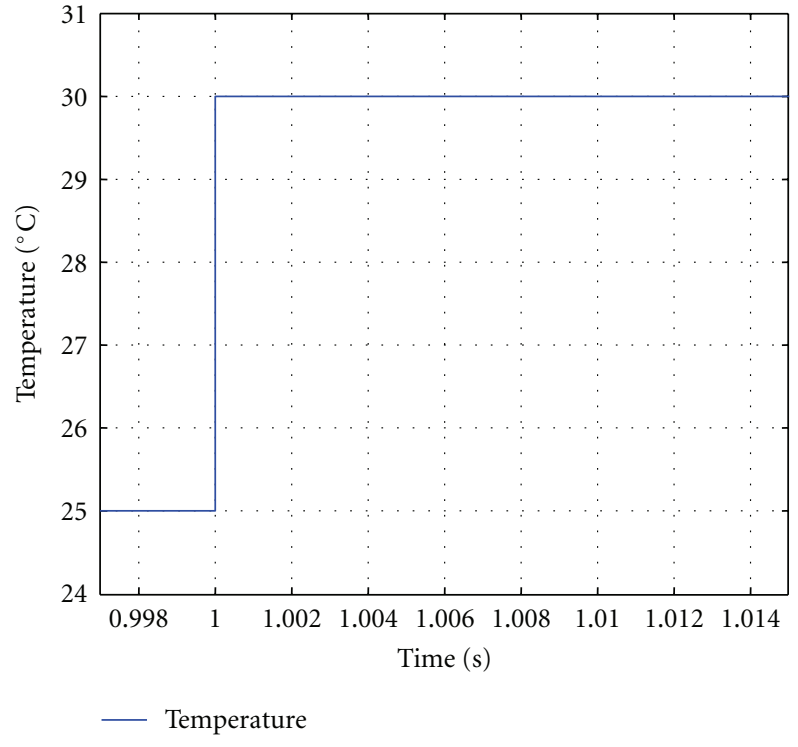

Figure 20: Drastic temperature changes from $25^{\circ} \mathrm{C}$ to $30^{\circ} \mathrm{C}$.

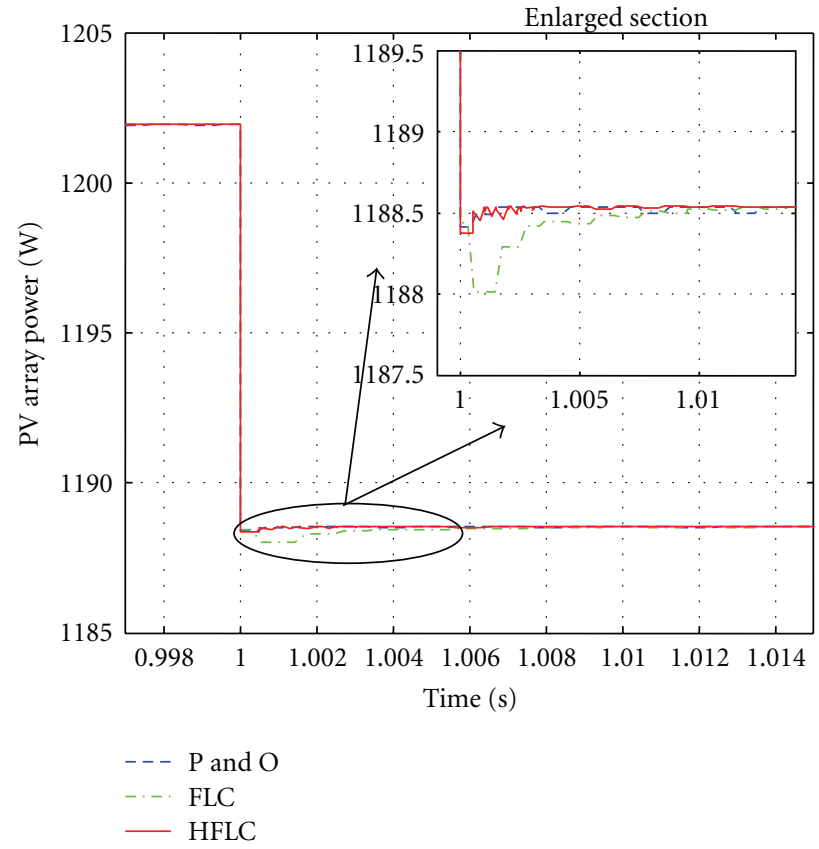

Figure 21: PV output power under sudden temperature change from $25^{\circ} \mathrm{C}$ to $30^{\circ} \mathrm{C}$.

and it is change in energy is given by

$$
\Delta E=-\left[\sum_{j} \mathrm{o}_{-} N_{j} \cdot w_{i j}+I_{i}\right] \Delta \mathrm{o}_{-} N_{i} .
$$

$d E / d t$ is always less than zero because $g$ is a monotonically increasing function. Therefore, the network solution moves in the same direction as the decrease in energy. The solution seeks out a minimum of $E$ and comes to a stop at stability point. 


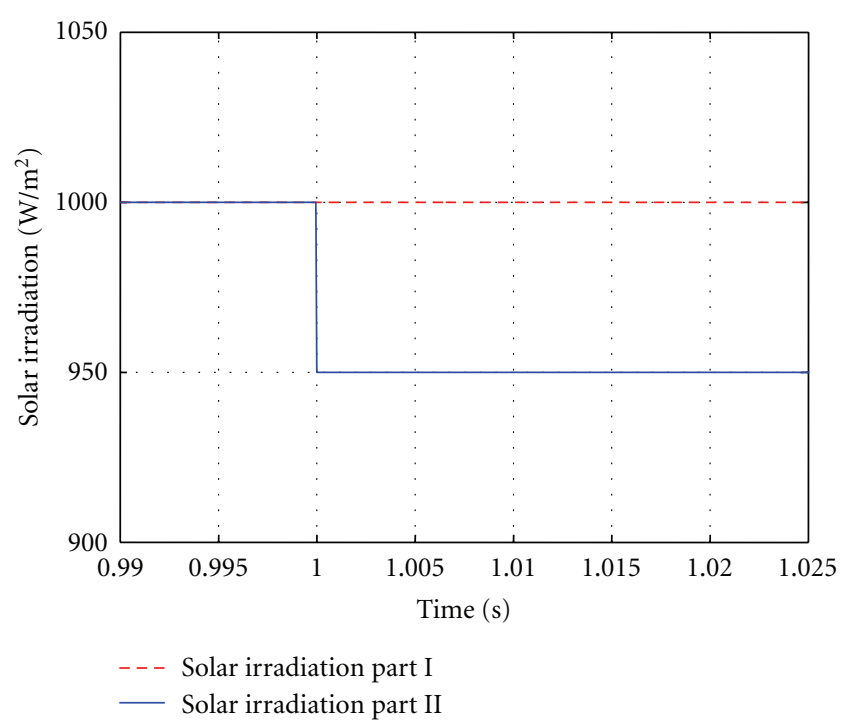

FIGURe 22: Partial shading of solar irradiation change.

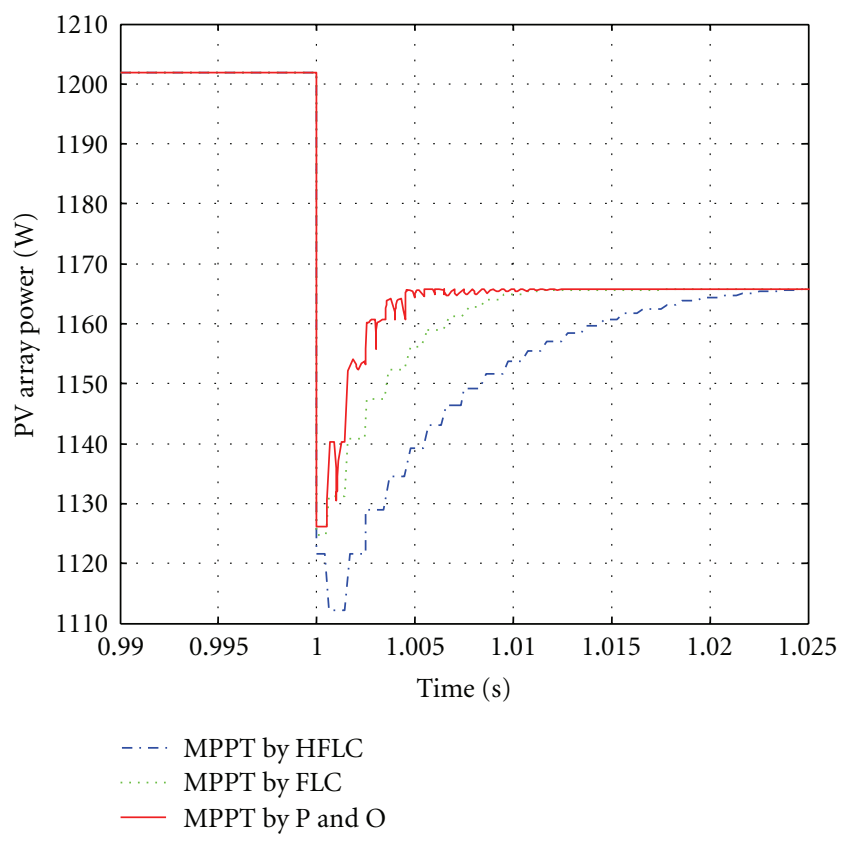

FIGURE 23: PV output power under partial shading with of solar irradiation change $1000 \mathrm{~W} / \mathrm{m}^{2}$ to $950 \mathrm{~W} / \mathrm{m}^{2}$.

3.2. Integrating HNN and FLC. Despite using expert knowledge in the formulation of the inference rules and the membership functions of FLC, there are still some defects such as center of fuzzification and range of the fuzzification. To improve these defects, the proposed FLC uses HNN to find the optimal membership functions which is achieved by considering the following steps.

(1) Defining neuron for the HNN. In the design of the proposed optimal FLC, two inputs, $\Delta P_{\mathrm{pv}}^{k}$ and direction $\Delta D^{k}$, and one output, $\Delta D_{\text {ref }}^{k}$, are used as described before. For

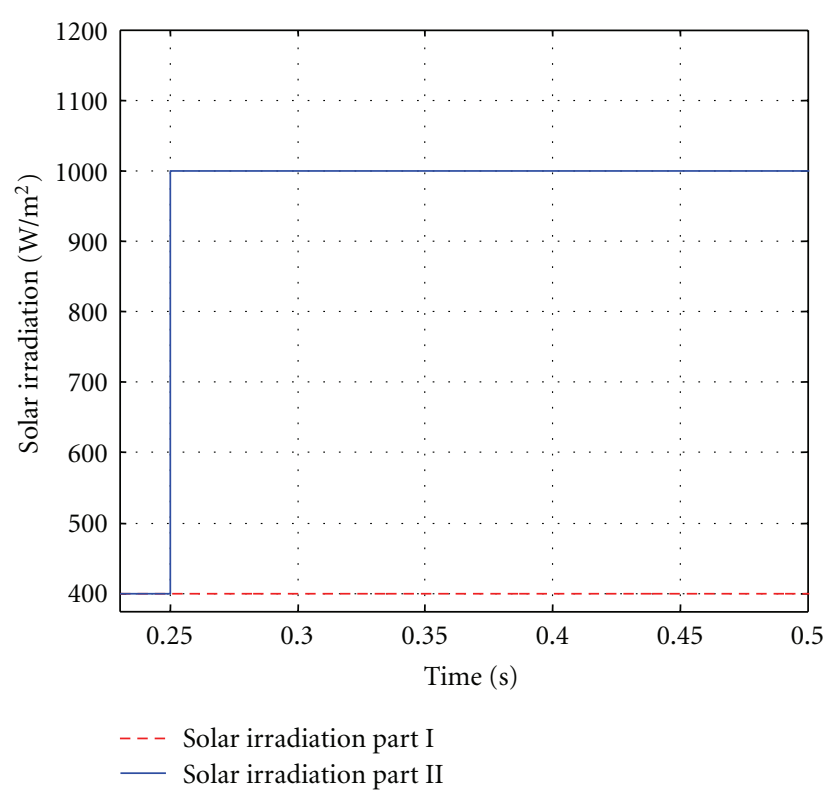

FIgure 24: Partial change of solar irradiation $400 \mathrm{~W} / \mathrm{m}^{2}$ to $1000 \mathrm{~W} / \mathrm{m}^{2}$

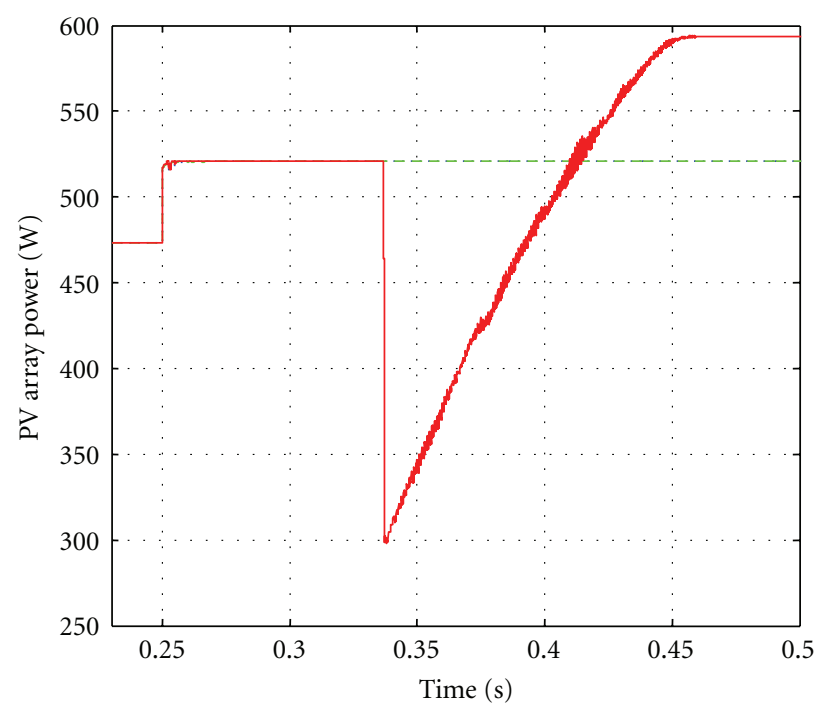

$$
\begin{aligned}
& \ldots . . \text { MPPT by P and } \mathrm{O} \\
& \ldots-\text { MPPT by FLC } \\
& - \text { MPPT by HFLC }
\end{aligned}
$$

FIGURE 25: PV output power under partial change of irradiation $400 \mathrm{~W} / \mathrm{m}^{2}$ to $1000 \mathrm{~W} / \mathrm{m}^{2}$.

simplicity, the design is only based on membership functions of $\Delta P_{\mathrm{pv}}^{k}$ and $\Delta D_{\mathrm{ref}}^{k} . \Delta P_{\mathrm{pv}}^{k}$ is described with seven membership functions, as illustrated in Figure 6, and $\Delta D_{\text {ref }}^{k}$ is described with nine membership functions, as illustrated in Figure 7. In Figure 6, the centers of $\Delta P_{\mathrm{pv}}^{k}$ membership function are $x_{1}, x_{2}, x_{3}, x_{4}, x_{5}, x_{6}$, and $x_{7}$ while in Figure 7 , the centers of $\Delta D_{\text {ref }}^{k}$ membership function are $z_{1}, z_{2}, z_{3}, z_{4}, z_{5}, z_{6}, z_{7}, z_{8}$, and $z_{9}$. Based on the number of centers of $\Delta P_{\mathrm{pv}}^{k}$ and $\Delta D_{\text {ref }}^{k}$, the proposed HNN consists of 16 neurons with variables given 


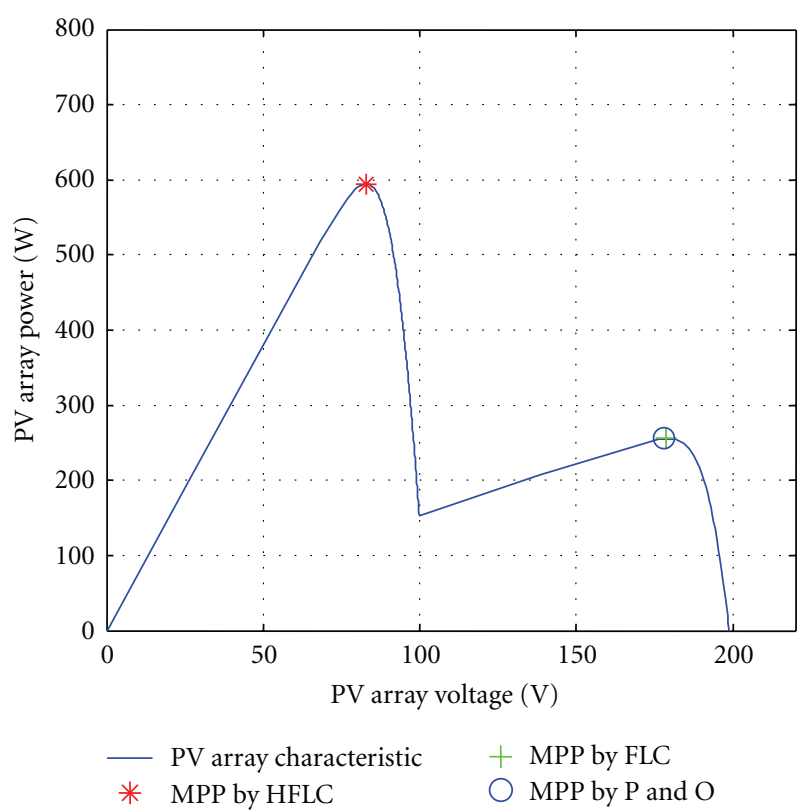

FIGURE 26: MPP under partial shading $200 \mathrm{~W} / \mathrm{m}^{2}$ and $1000 \mathrm{~W} / \mathrm{m}^{2}$.

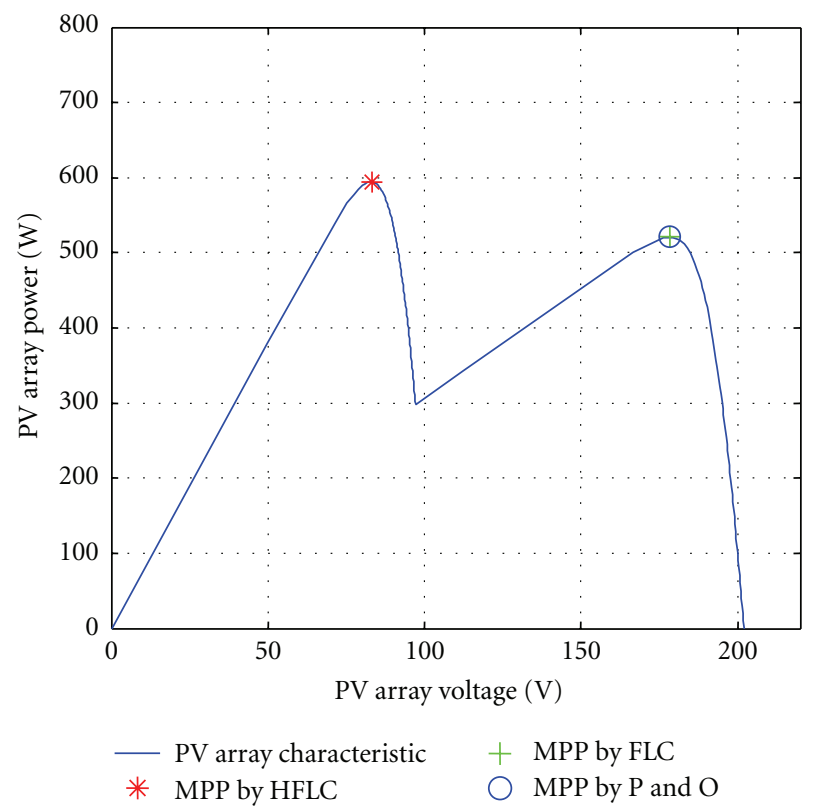

FIGURE 27: MPP under partial shading $400 \mathrm{~W} / \mathrm{m}^{2}$ and $1000 \mathrm{~W} / \mathrm{m}^{2}$. $S_{P 6} ; x_{7}=S_{P 7} ; z_{1}=-S_{D 1} ; z_{2}=-S_{D 2} ; z_{3}=-S_{D 3} ; z_{4}=-S_{D 4}$; $z_{5}=S_{D 5} ; z_{6}=S_{D 6} ; z_{7}=S_{D 7} ; z_{8}=S_{D 8} ; z_{9}=S_{D 9} . S_{P 1}-S_{P 7}$ are output value of neurons $N_{1}-N_{7}\left(o_{-} N_{1}-O_{-} N_{7}\right)$ while $S_{D 1}-S_{D 9}$ are output values of neurons $N_{8}-N_{16}\left(\mathrm{o} \_N_{8}-\mathrm{O} \_N_{16}\right)$.

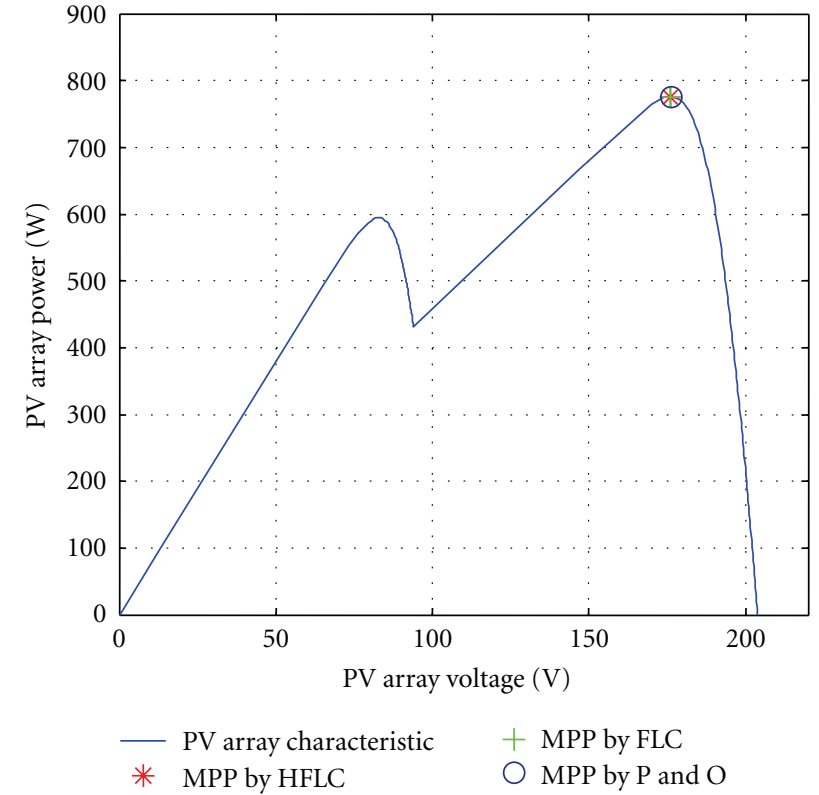

FIGURE 28: MPP under partial shading $600 \mathrm{~W} / \mathrm{m}^{2}$ and $1000 \mathrm{~W} / \mathrm{m}^{2}$.

When comparing the values of neurons in Figures 6 and 7 , the following constraints should be satisfied.

$$
\begin{gathered}
S_{P 4}=0, \\
S_{P 1}=S_{P \text { max_left }}, \\
S_{P 7}=S_{P \text { max_right }}, \\
0 \leq S_{P 3} \leq S_{P 2} \leq S_{P 1}, \\
0 \leq S_{P 6} \leq S_{P 5} \leq S_{P 7}, \\
S_{D 5}=0 \\
S_{D 1}=S_{D \text { max_left }}, \\
S_{D 9}=S_{D \text { max_right }}, \\
0 \leq S_{D 4} \leq S_{D 3} \leq S_{D 2} \leq S_{D 1}, \\
0 \leq S_{D 6} \leq S_{D 7} \leq S_{D 8} \leq S_{D 9} .
\end{gathered}
$$

(2) Defining objective function for the optimization problem. The goal of MPPT is to achieve $\Delta P_{\mathrm{pv}}^{k}=0$ and $\Delta D_{\mathrm{ref}}^{k}=0$. Therefore, the quadratic criterion to be minimized is

$$
E=E_{1}+E_{2}=\frac{1}{2} A\left(\Delta P_{\mathrm{pv}}^{k}\right)^{2}+\frac{1}{2} B\left(\Delta D_{\mathrm{ref}}^{k}\right)^{2}
$$

where, $E$ : energy function to be minimized, $A, B$ : constants.

From (11), the first part of $E$, which is $E_{1}=$ $(1 / 2) A\left(\Delta P_{\mathrm{pv}}^{k}\right)^{2}$ only depends on the universe of $\Delta P_{\mathrm{pv}}^{k}$ which is in the first input of FLC. The $\Delta P_{\mathrm{pv}}^{k}$ is defined by 


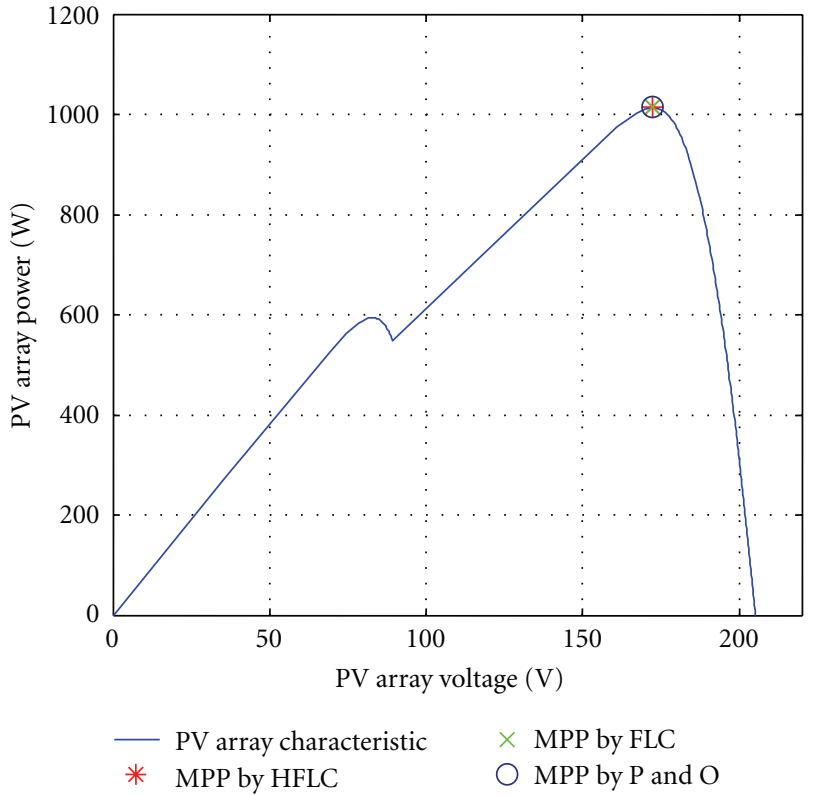

FIGURE 29: MPP under partial shading $800 \mathrm{~W} / \mathrm{m}^{2}$ and $1000 \mathrm{~W} / \mathrm{m}^{2}$.

defuzzification of the universe of $\Delta P_{\mathrm{pv}}^{k}$ using a centroid function as:

$$
\Delta P_{\mathrm{pv}}^{k}=\frac{\sum_{i=1}^{7} \mu\left(\Delta P_{\mathrm{pv}}^{k}\right)_{i} x_{i}}{\sum_{i=1}^{7} \mu\left(\Delta P_{\mathrm{pv}}^{k}\right)_{i}}
$$

where $\mu\left(\Delta P_{\mathrm{pv}}^{k}\right)_{i}$ is a membership value of $x_{i}$.

$E_{1}$ depends only on neurons $N_{i}(i=1,2,3,4,5,6,7)$. Knowing that the left side of $\Delta P_{\mathrm{pv}}^{k}$ in the membership function of the first input is $\mu\left(\Delta P_{\mathrm{pv}}^{k}\right)_{i} \neq 0$ for $x_{1}, x_{2}, x_{3}$, then, $\Delta P_{\mathrm{pv}}^{k}$ can be rewritten as

$$
\Delta P_{\mathrm{pv}}^{k}=\frac{\sum_{i=1}^{3} \mu\left(\Delta P_{\mathrm{pv}}^{k}\right)_{i} x_{i}}{\sum_{i=1}^{7} \mu\left(\Delta P_{\mathrm{pv}}^{k}\right)_{i}} .
$$

Then, the first half of energy function $E_{1}$ can be rewritten as $E_{1 a}$ :

$$
\begin{aligned}
E_{1 a}= & \frac{1}{2} A\left[\frac{\sum_{i=1}^{3} \mu\left(\Delta P_{\mathrm{pv}}^{k}\right)_{i} x_{i}}{\sum_{i=1}^{7} \mu\left(\Delta P_{\mathrm{pv}}^{k}\right)_{i}}\right]^{2}, \\
E_{1 a}= & \frac{1}{2} \frac{A}{\sum_{i=1}^{7} \sum_{j}^{7} \mu\left(\Delta P_{\mathrm{pv}}^{k}\right)_{i} \mu\left(\Delta P_{\mathrm{pv}}^{k}\right)_{j}} \\
& \times\left(\sum_{i=1}^{3} \sum_{j=1}^{3} \mu\left(\Delta P_{\mathrm{pv}}^{k}\right)_{i} \mu\left(\Delta P_{\mathrm{pv}}^{k}\right)_{j}\left(-\mathrm{o}_{-} N\right)_{i}\left(-\mathrm{o}_{-} N\right)_{j}\right) \\
E_{1 a}= & \frac{1}{2}\left[\sum_{i=1}^{3} \sum_{j}^{3}\left[\frac{A \mu\left(\Delta P_{\mathrm{pv}}^{k}\right)_{i} \mu\left(\Delta P_{\mathrm{pv}}^{k}\right)_{j}}{\sum_{i=1}^{7} \sum_{j}^{7} \mu\left(\Delta P_{\mathrm{pv}}^{k}\right)_{i} \mu\left(\Delta P_{\mathrm{pv}}^{k}\right)_{j}}\right] o_{-} N_{i} \cdot o_{-} N_{j}\right] .
\end{aligned}
$$

Considering that the right side and center of $\Delta P_{\mathrm{pv}}^{k}$ in the membership function of the first input of FLC is $\mu\left(\Delta P_{\mathrm{pv}}^{k}\right)_{i}=$ 0 for $x_{1}, x_{2}, x_{3}$, hence $\Delta P_{\mathrm{pv}}^{k}$ can be rewritten as:

$$
\Delta P_{\mathrm{pv}}^{k}=\frac{\sum_{i=4}^{7} \mu\left(\Delta P_{\mathrm{pv}}^{k}\right)_{i} x_{i}}{\sum_{i=4}^{7} \mu\left(\Delta P_{\mathrm{pv}}^{k}\right)_{i}}
$$

Similarly, the second half of energy function $E_{1}$ is rewritten as $E_{1 b}$ :

$E_{1 b}=\frac{1}{2}\left[\sum_{i=5}^{7} \sum_{j=5}^{7}\left[\frac{A \mu\left(\Delta P_{\mathrm{pv}}^{k}\right)_{i} \mu\left(\Delta P_{\mathrm{pv}}^{k}\right)_{j}}{\sum_{i=1}^{7} \sum_{j=1}^{7} \mu\left(\Delta P_{\mathrm{pv}}^{k}\right)_{i} \mu\left(\Delta P_{\mathrm{pv}}^{k}\right)_{j}}\right] \mathrm{o}_{-} N_{i} \cdot \mathrm{o}_{-} N_{j}\right]$.

Since the first part of $E_{1}$ is the summation of left side $\left(E_{1 a}\right)$ and right side $\left(E_{1 b}\right)$ of the $\Delta P_{\mathrm{pv}}^{k}$ membership function, $E_{1}$ can be expressed as:

$$
E_{1}=\frac{1}{2} A\left(\Delta P_{\mathrm{pv}}^{k}\right)^{2}=E_{1 a}+E_{1 b},
$$

$E_{1}=\frac{1}{2}\left[\sum_{i=4}^{7} \sum_{j=4}^{7}\left[\frac{A \mu\left(\Delta P_{\mathrm{pv}}^{k}\right)_{i} \mu\left(\Delta P_{\mathrm{pv}}^{k}\right)_{j}}{\sum_{i=1}^{7} \sum_{j=1}^{7} \mu\left(\Delta P_{\mathrm{pv}}^{k}\right)_{i} \mu\left(\Delta P_{\mathrm{pv}}^{k}\right)_{j}}\right] o_{-} N_{i} \cdot \mathrm{o}_{-} N_{j}\right]$,

where $\mathrm{o} \_N=0$ for $i=4, j=4$.

The second part, $E_{2}=(1 / 2) B\left(\Delta D_{\text {ref }}^{k}\right)^{2}$ is related to the output of FLC and depends only on neurons $N_{i}(i=$ $8,9,10,11,12,13,14,15,16)$. The $\Delta D_{\text {ref }}^{k}$ can be defined by defuzzification by using the centroid method and is written as:

$$
\Delta D_{\mathrm{ref}}^{k}=\frac{\sum_{k=1}^{9} \mu\left(\Delta D_{\mathrm{ref}}^{k}\right)_{m} z_{m}}{\sum_{k=1}^{9} \mu\left(\Delta D_{\mathrm{ref}}^{k}\right)_{m}}
$$

Similar to the equations shown in obtaining $E_{1}, E_{2}$ can be expressed as

$$
\begin{aligned}
& E_{2}=\frac{1}{2}\left[\sum_{m=1}^{9} \sum_{n=1}^{9}\left[\frac{B \mu\left(\Delta D_{\mathrm{ref}}^{k}\right)_{m} \mu\left(\Delta D_{\mathrm{ref}}^{k}\right)_{n}}{\sum_{m=1}^{9} \sum_{n=1}^{9} \mu\left(\Delta D_{\mathrm{ref}}^{k}\right)_{m} \mu\left(\Delta D_{\mathrm{ref}}^{k}\right)_{n}}\right] z_{m} z_{n}\right], \\
& E_{2}=\frac{1}{2}\left[\sum_{i=8}^{16} \sum_{j=8}^{16}\left[\frac{B \mu\left(\Delta D_{\mathrm{pv}}^{k}\right)_{i} \mu\left(\Delta D_{\mathrm{pv}}^{k}\right)_{j}}{\sum_{i=8}^{16} \sum_{j=8}^{16} \mu\left(\Delta D_{\mathrm{pv}}^{k}\right)_{i} \mu\left(\Delta D_{\mathrm{pv}}^{k}\right)_{j}}\right] \mathrm{o}_{-} N_{i} \cdot \mathrm{o}_{-} N_{j}\right],
\end{aligned}
$$

where $N=0$ for $i=12, j=12$ and $\mu\left(\Delta D_{\text {ref }}^{k}\right)$ is the membership value of $z_{n}$. 
Finally, the total energy function $E$ is expressed as

$$
\begin{aligned}
E= & E_{1}+E_{2}, \\
E= & \frac{1}{2}\left[\sum_{i=1}^{7} \sum_{j=1}^{7}\left[\frac{A \mu\left(\Delta P_{\mathrm{pv}}^{k}\right)_{i} \mu\left(\Delta P_{\mathrm{pv}}^{k}\right)_{j}}{\sum_{i=1}^{7} \sum_{j=1}^{7} \mu\left(\Delta P_{\mathrm{pv}}^{k}\right)_{i} \mu\left(\Delta P_{\mathrm{pv}}^{k}\right)_{j}}\right] \mathrm{o}_{-} N_{i} \cdot \mathrm{o}_{-} N_{j}\right] \\
& +\frac{1}{2}\left[\sum_{i=8}^{16} \sum_{j=8}^{16}\left[\frac{B \mu\left(\Delta D_{\mathrm{ref}}^{k}\right)_{i} \mu\left(\Delta D_{\mathrm{ref}}^{k}\right)_{j}}{\sum_{i=8}^{16} \sum_{j=8}^{16} \mu\left(\Delta D_{\mathrm{ref}}^{k}\right)_{i} \mu\left(\Delta D_{\mathrm{ref}}^{k}\right)_{j}}\right] \mathrm{o}_{-} N_{i} \cdot \mathrm{o}_{-} N_{j}\right] .
\end{aligned}
$$

where $N=0$ for $i=4,12 ; j=4,12$.

By comparing (8) with (20), the weight matrix of neurons $N_{i}$ to $N_{j}$ in the HNN is derived and given as:

$$
w_{i j}=\left[\begin{array}{ccccc}
w_{11} & w_{12} & w_{13} & \ldots & 0 \\
w_{21} & w_{22} & & & \\
w_{31} & w_{32} & & & \\
\vdots & & & & \\
0 & 0 & 0 & & w_{n n}
\end{array}\right] \text {, }
$$

where,

$$
\begin{aligned}
& w_{i j}=-\frac{A \mu\left(\Delta P_{\mathrm{pv}}^{k}\right)_{i} \mu\left(\Delta P_{\mathrm{pv}}^{k}\right)_{j}}{\sum_{i=1}^{7} \sum_{j=1}^{7} \mu\left(\Delta P_{\mathrm{pv}}^{k}\right)_{i} \mu\left(\Delta P_{\mathrm{pv}}^{k}\right)_{j}}, \\
& \text { for } i \text { and } j=1,2,3,4,5,6,7, \\
& w_{i j}=-\frac{B \mu\left(\Delta D_{\mathrm{ref}}^{k}\right)_{i} \phi \mu\left(\Delta D_{\mathrm{ref}}^{k}\right)_{j}}{\sum_{i=8}^{16} \sum_{j=8}^{16} \mu\left(\Delta D_{\mathrm{ref}}^{k}\right)_{i} \mu\left(\Delta_{\mathrm{ref}}^{k}\right)_{j}}, \\
& \text { for } i, j=8,9,10,11,12,13,14,15,16, \\
& w_{i j}=0, \quad \text { for other. }
\end{aligned}
$$

(3) Design for Physical Implementation. The physical implementation of MPPT for PV systems using Hopfield optimized FLC (HFLC) is described in terms of a block diagram as shown in Figure 8.

As shown in Figure 8, the system consists of PV array, DC-DC converter, load, and control system. The control system consist of voltage and current measurement system, controlled pulse with modulation (PWM) generator with HFLC, and a switching driver circuit to gain the PWM. At the initial step $(k=0)$, the control system generates square wave signals with a small duty cycle $(D)$, of value $10 \%$. In the next step $(k=1)$, the value of $D$ is increased by $\Delta D_{\text {ref }}^{k}$ that is defined by HFLC as discussed in the previous section. The value of $D$ is always updated by the increment $\Delta D_{\text {ref }}^{k}$. The value of $\Delta D_{\text {ref }}^{k}$ tends to change in either positive or negative direction as $\left|\Delta D_{\text {ref }}^{k}\right|$ decline towards zero.

\section{Simulation Results}

The performance of the proposed HFLC under different operating conditions is validated using the MATLAB/Simulink software. In the PV model shown in Figure 9, there are two groups of PV arrays connected in parallel. Every group consists of $3 \mathrm{PV}$ modules connected in series. The PV module parameters are obtained from the Sanyo HIP-200BA3 PV technical datasheet [24]. In the simulations, first the characteristics of the PV module are validated and then the performance of the HFLC under various conditions is evaluated to investigate the effectiveness of the HFLC method.

4.1. Validation of $P V$ Module Simulation. Figures 10 and 11 show the results of the $I-V$ characteristics of the simulated PV module as a function of irradiation and temperature, respectively. It can be observed from the above figures that the $I-V$ curves of the simulated PV module are quite similar to the $I-V$ curves of the Sanyo HIP-200BA3 PV module provided by the Sanyo manufacturer in Figure 1. Therefore, it is quite reasonable to use the PV module model to verify the performance of the proposed HFLC-based MPPT controller under simulation environment.

4.2. Performance of MPPT by Using HFLC. Figures 12 and 13 show the performance of the HFLC in finding the maximum power point (MPP) of the PV system shown in Figure 9 under varying irradiations and temperatures, respectively. From the figures, the MPP obtained from HFLC is compared with the theoretical MPP. The results of the MPP clearly show that both MPPs are very close to each other.

To further demonstrate the performance of the HFLC MPPT controller, simulations were performed under the following test conditions.

(i) Constant temperature at $25^{\circ} \mathrm{C}$ and changing the solar radiation slowly and drastically.

(ii) Constant solar radiation at $1000 \mathrm{~W} / \mathrm{m}^{2}$ and changing the temperature slowly and drastically.

(iii) Constant temperature at $25^{\circ} \mathrm{C}$ and considering partial shading and change in solar radiation.

The MPPT controller was also tested using the conventional FLC and the P\&O MPPT methods.

4.2.1. Effect of Changing the Solar Radiation. To analyze the effect of solar radiation, simulations were carried out under various solar irradiations but at constant temperature of $25^{\circ} \mathrm{C}$. Figure 14 shows the change in solar irradiation from $1000 \mathrm{~W} / \mathrm{m}^{2}$ to $900 \mathrm{~W} / \mathrm{m}^{2}$. Figure 15 shows the PV output power when subjected to the changing solar irradiations. From Figure 15, it can be seen that the HFLC, and FLC-based MPPT gives greater PV output powers than the P\&O-based MPPT.

Figure 16 shows the sudden change in solar irradiation from $1000 \mathrm{~W} / \mathrm{m}^{2}$ to $950 \mathrm{~W} / \mathrm{m}^{2}$ while Figure 17 shows the response of the MPPT controller in terms of PV output 
TABLE 2: Various partial shaded solar irradiation.

\begin{tabular}{lcc}
\hline No. & \multicolumn{2}{c}{ Solar irradiation $\left(\mathrm{W} / \mathrm{m}^{2}\right)$} \\
& Part I & Part II \\
\hline$(1)$ & 1000 & 200 \\
$(2)$ & 1000 & 400 \\
$(3)$ & 1000 & 600 \\
$(4)$ & 1000 & 800 \\
\hline
\end{tabular}

power when subjected to a sudden change in solar irradiation. From the figures, it is noted that the PV output power is greatest for MPPT controlled by HFLC compared to that of FLC and P\&O methods. Furthermore, MPPT controlled by HFLC gives a fast response to reach the new MPP after solar irradiation changes.

4.2.2. Effect of Change in Temperature. This simulation is carried out to illustrate the performance of the MPPT methods under constant solar irradiation of $1000 \mathrm{~W} / \mathrm{m}^{2}$ and changes in temperature. Figures 18 and 20 depict the slow and sudden changes in temperature, respectively. Figures 19 and 21 show the corresponding PV output powers during slow and sudden changes in temperature, respectively. From Figure 19, it can be noted that for slow temperature changes, the MPPT controlled by HFLC and FLC gives higher PV output power than the P\&O method especially at the transient state. While in the case of drastic change in temperature, the MPPT controlled by HFLC achieve the highest PV output at the transient state as shown in Figure 21.

4.2.3. Effect of Partial Shaded Solar Irradiation. Simulation is also performed to illustrate the effectiveness of the MPPT of PV systems under some partial shading case. In this case, it is assumed that a half of the PV array receives constant solar irradiation of $1000 \mathrm{~W} / \mathrm{m}^{2}$ and the other half with shading solar irradiation which changes from $1000 \mathrm{~W} / \mathrm{m}^{2}$ to $950 \mathrm{~W} / \mathrm{m}^{2}$. This condition is depicted in Figure 22 . The power harvested from the PV array for this case is shown in Figure 23. From Figure 23, it can be seen that performance of MPPT controlled by HFLC is the best among the other compared methods.

Another case describes a situation of solar irradiation changing from $400 \mathrm{~W} / \mathrm{m}^{2}$ to $1000 \mathrm{~W} / \mathrm{m}^{2}$, to a half of the PV array while the other half receiving constant $400 \mathrm{~W} / \mathrm{m}^{2}$ under shading as shown in Figure 24. The PV output power for this case is shown in Figure 25. From the figure, it can be noted that the FLC and P\&O failed to track the MPP correctly. However, the proposed HFLC MPPT method successfully finds the MPP around $590 \mathrm{~W}$ as shown in Figure 25.

Figures 26, 27, 28, and 29 show the characteristic curves of voltage versus power $(V-P)$ of the modeled PV array under various partial shading conditions described in Table 2.

From Figures 26 and 27, it can be seen that the HFLC method is accurate in finding the MPP $(590 \mathrm{~W})$ while the conventional FLC and $\mathrm{P} \& \mathrm{O}$ methods failed to do so. Generally, the conventional FLC and P\&O methods just find local maximum power point. However, for case as depicted in Figures 28 and 29, all of the MPPT methods correctly tracked the MPP.

\section{Conclusion}

A new Hopfield optimized FLC for MPPT of PV system is proposed in which improvement is made by applying HNN to find the optimal width of each fuzzification input and output of the FLC. A complete PV system with HFLC MPPT controller was modeled and implemented in Matlab/Simulink to simulate various irradiation and temperature conditions so as to verify the performance of the proposed MPPT method. Simulation results show that the proposed HFLC MPPT method is robust and accurate compared to the other conventional MPPT methods. The HFLC MPPT method successfully tracks the global maximum power point of a PV module even under partial shading.

\section{References}

[1] T. J. Hammons, J. C. Boyer, S. R. Conners et al., "Renewable energy alternatives for developed countries," IEEE Transactions on Energy Conversion, vol. 15, no. 4, pp. 481-493, 2000.

[2] F. Blaabjerg, C. Zhe, and R. Teodorescu, "Renewable energy systems in the power electronics curriculum," in Proceedings of the IEEE Power Electronics Education Workshop, vol. 2005, pp. 58-68, 2005.

[3] M. A. Eltawil and Z. Zhao, "Grid-connected photovoltaic power systems: technical and potential problems-a review," Renewable and Sustainable Energy Reviews, vol. 14, no. 1, pp. 112-129, 2010.

[4] V. Salas, E. Olías, A. Barrado, and A. Lázaro, "Review of the maximum power point tracking algorithms for stand-alone photovoltaic systems," Solar Energy Materials and Solar Cells, vol. 90, no. 11, pp. 1555-1578, 2006.

[5] T. Esram and P. L. Chapman, "Comparison of photovoltaic array maximum power point tracking techniques," IEEE Transactions on Energy Conversion, vol. 22, no. 2, pp. 439-449, 2007.

[6] N. S. D’Souza, L. A. C. Lopes, and X. J. Liu, "An intelligent maximum power point tracker using peak current control," in Proceedings of the IEEE 36th Power Electronics Specialists Conference (PESC '05), pp. 172-177.

[7] M. S. A. Cheikh, C. Larbes, G. F. T. Kebir, and A. Zerguerras, "Maximum power point tracking using a fuzzy logic control scheme," Revue des Energies Renouvelables, vol. 10, no. 3, pp. 387-395, 2007.

[8] S. Lalouni, D. Rekioua, T. Rekioua, and E. Matagne, "Fuzzy logic control of stand-alone photovoltaic system with battery storage," Journal of Power Sources, vol. 193, no. 2, pp. 899-907, 2009.

[9] A. Moreno, J. Julve, S. Silvestre, and L. Castaner, "A fuzzy logic controller for stand alone PV systems," in Proceedings of the IEEE Photovoltaic Specialists Conference, pp. 1618-1621, 2000.

[10] N. Patcharaprakiti and S. Premrudeepreechacharn, "Maximum power point tracking using adaptive fuzzy logic control for grid-connected photovoltaic system," in Proceedings of the IEEE Power Engineering Society Winter Meeting, pp. 372-377, January 2002. 
[11] A. Messai, A. Mellit, A. Guessoum, and S. A. Kalogirou, "Maximum power point tracking using a GA optimized fuzzy logic controller and its FPGA implementation," Solar Energy, vol. 85, no. 2, pp. 265-277, 2011.

[12] L. K. Letting, J. L. Munda, and A. Hamam, "Particle swarm optimized T-S fuzzy logic controller for maximum power point tracking in a photovoltaic system," in Proceedings of the 9th International Power and Energy Conference (IPEC'10), pp. 89-94, 2010.

[13] N. Khaehintung, A. Kunakorn, and P. Sirisuk, "A novel fuzzy logic control technique tuned by particle swarm optimization for maximum power point tracking for a photovoltaic system using a current-mode boost converter with bifurcation control," International Journal of Control, Automation and Systems, vol. 8, no. 2, pp. 289-300, 2010.

[14] S. Premrudeepreechacham and N. Patanapirom, "Solar-array modelling and maximum power point tracking using neural networks," in Proceedings of the International Power Tech Conference, vol. 2, pp. 5-9, Bologna, Italy, 2003.

[15] K. H. Chao, C. J. Li, and M. H. Wang, "A maximum power point tracking method based on extension neural network for PV systems," Advances in Neural Networks, vol. 5551, pp. 745755, 2009.

[16] M. Habibi and A. Yazdizadeh, "New MPPT controller design for PV arrays using neural networks," Advances in Neural Networks, vol. 5552, pp. 1050-1058, 2009.

[17] M. Veerachary, T. Senjyu, and K. Uezato, "Neural-networkbased maximum-power-point tracking of coupled-inductor interleaved-boost-converter-supplied PV system using fuzzy controller," IEEE Transactions on Industrial Electronics, vol. 50, no. 4, pp. 749-758, 2003.

[18] A. Mellit and S. A. Kalogirou, "Artificial intelligence techniques for photovoltaic applications: a review," Progress in Energy and Combustion Science, vol. 34, no. 5, pp. 574-632, 2008.

[19] J. J. Hopfield, "Neural networks and physical systems with emergent collective computational abilities," Proceedings of the National Academy of Sciences of the United States of America, vol. 79, no. 8, pp. 2554-2558, 1982.

[20] J. J. Hopfield, "Neurons with graded response have collective computational properties like those of two-state neurons," Proceedings of the National Academy of Sciences of the United States of America, vol. 81, no. 10 I, pp. 3088-3092, 1984.

[21] J. J. Hopfield and D. W. Tank, “"Neural” computation of decisions in optimization problems," Biological Cybernetics, vol. 52, no. 3, pp. 141-152, 1985.

[22] J. Mańdziuk, "Optimization with the Hopfield network based on correlated noises: experimental approach," Neurocomputing, vol. 30, no. 1-4, pp. 301-321, 2000.

[23] G. Joya, M. A. Atencia, and F. Sandoval, "Hopfield neural networks for optimization: study of the different dynamics," Neurocomputing, vol. 43, pp. 219-237, 2002.

[24] HIP-200BA3 Sanyo, technical sheet, 2006, http://www.fsuwise .org/renewable/Images/WISE_Demo_Syatem_Files/Sanyo_ 200W.pdf.

[25] S. Haykin, Neural Networks A Comprehensive Foundation, Pearson Education, Delhi, India, 9th edition, 2005. 


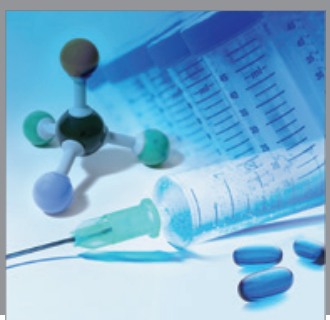

International Journal of

Medicinal Chemistry

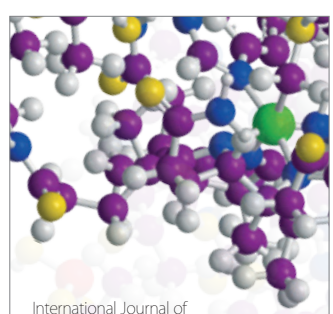

Carbohydrate Chemistry

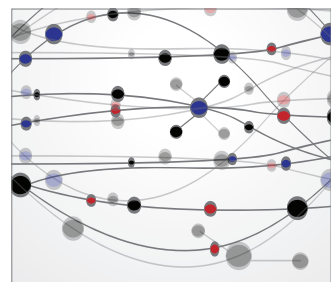

The Scientific World Journal
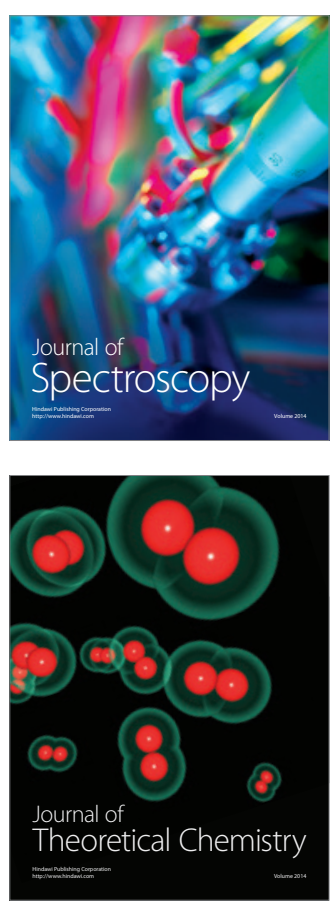
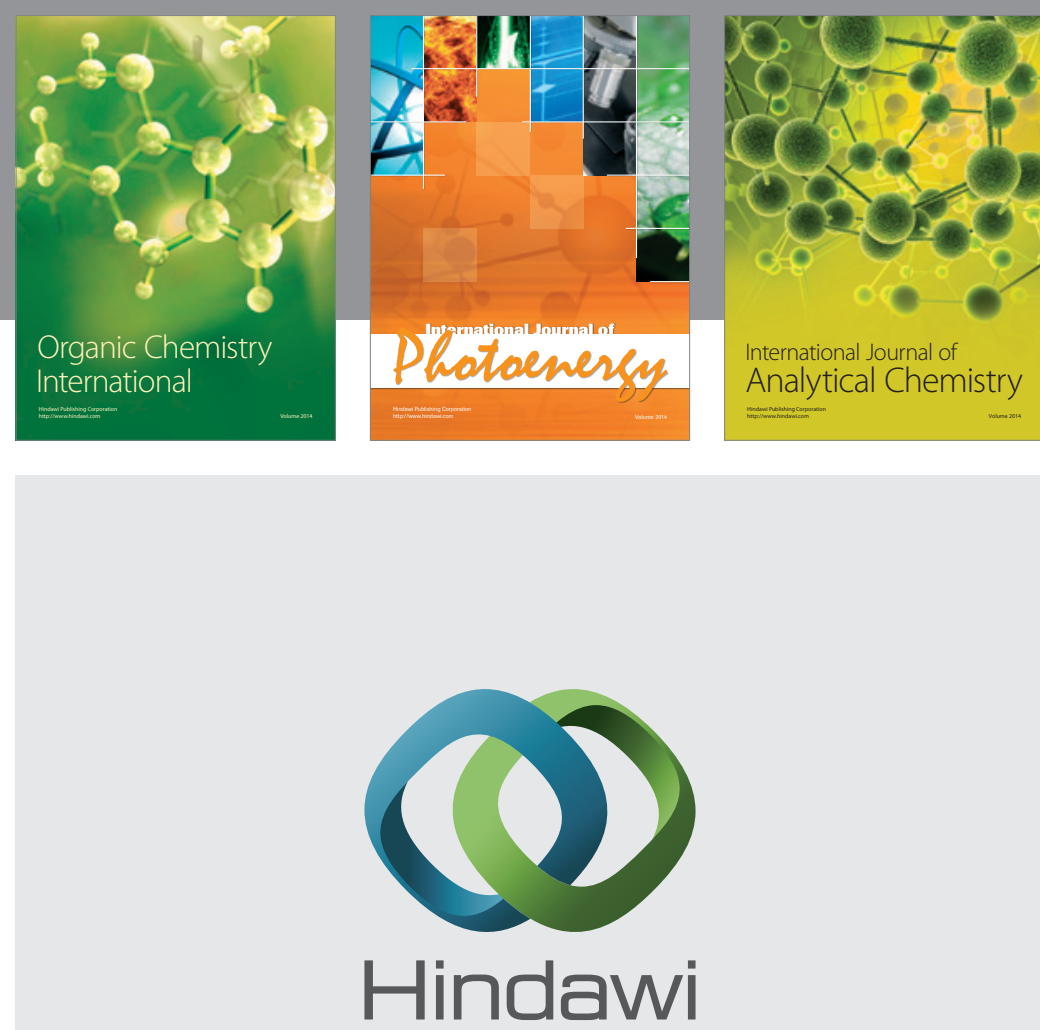

Submit your manuscripts at

http://www.hindawi.com
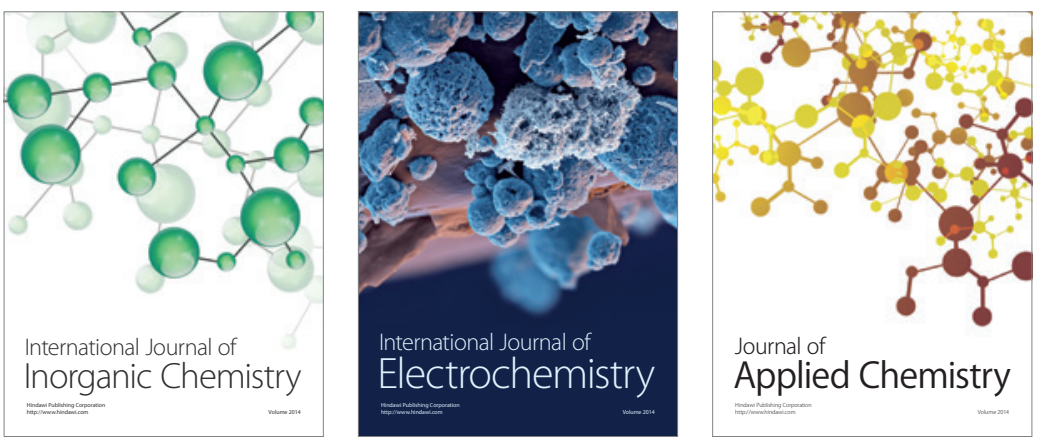

Journal of

Applied Chemistry
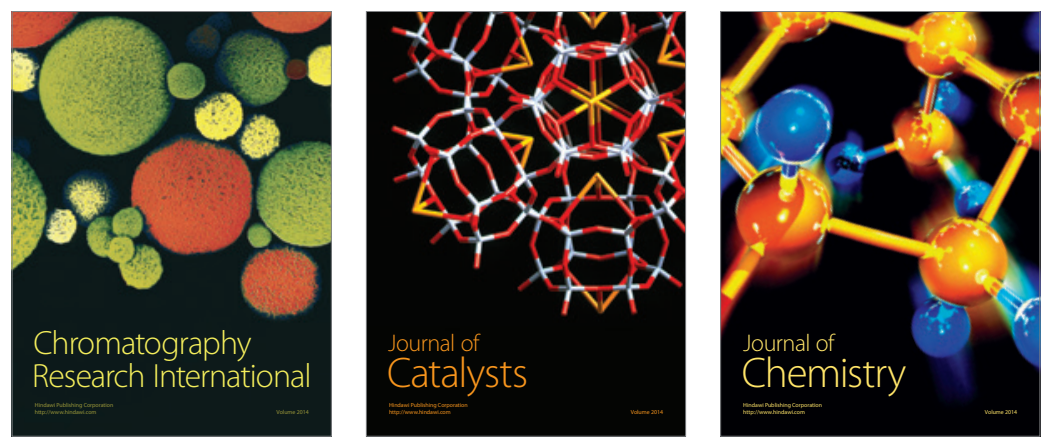
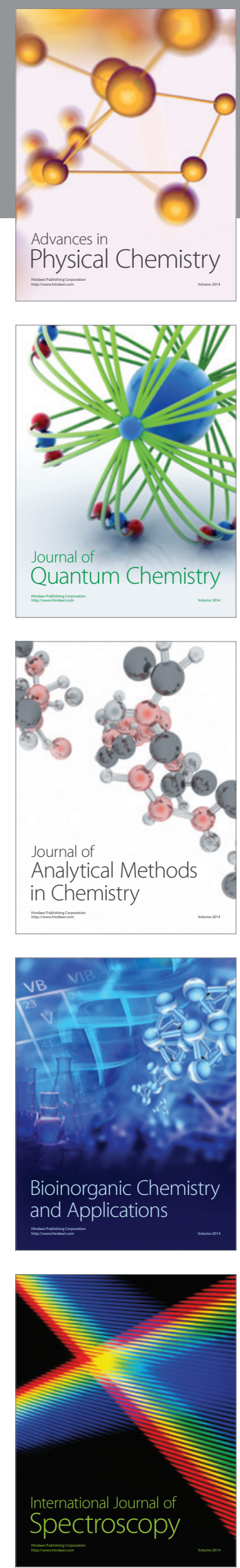